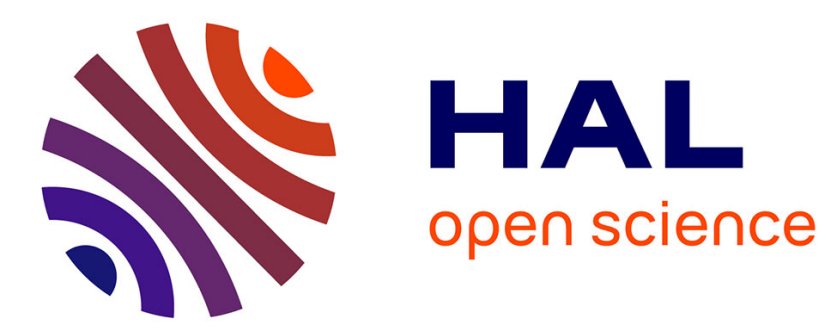

\title{
Overall Investigation of Poly (Phenylene Sulfide) from Synthesis and Process to Applications-A Review
}

Peiyuan Zuo, Abbas Tcharkhtchi, Mohammadali Shirinbayan, Joseph Fitoussi, Farid Bakir

\section{- To cite this version:}

Peiyuan Zuo, Abbas Tcharkhtchi, Mohammadali Shirinbayan, Joseph Fitoussi, Farid Bakir. Overall Investigation of Poly (Phenylene Sulfide) from Synthesis and Process to Applications-A Review. Macromolecular Materials and Engineering, 2019, 304 (5), pp.1-27. 10.1002/mame.201800686 . hal02471064

\section{HAL Id: hal-02471064 \\ https://hal.science/hal-02471064}

Submitted on 7 Feb 2020

HAL is a multi-disciplinary open access archive for the deposit and dissemination of scientific research documents, whether they are published or not. The documents may come from teaching and research institutions in France or abroad, or from public or private research centers.
L'archive ouverte pluridisciplinaire HAL, est destinée au dépôt et à la diffusion de documents scientifiques de niveau recherche, publiés ou non, émanant des établissements d'enseignement et de recherche français ou étrangers, des laboratoires publics ou privés. 


\title{
Overall Investigation of Poly (Phenylene Sulfide) from Synthesis and Process to Applications-A Review
}

\author{
Peiyuan Zuo, ${ }^{*}$ Abbas Tcharkhtchi, Mohammadali Shirinbayan, Joseph \\ Fitoussi, and Farid Bakir
}

Poly (phenylene sulfide) (PPS) is one kind of high-performance polymer with high thermal stability that can be used widely in different industrial domains. However, according to an investigation of the literature, few reviews have comprehensively focused on the continuous development of PPS applications in the past decade. To meet this demand, this paper provides an overall investigation of PPS polymer and PPS-based composites from synthesis and process to applications. Briefly, this paper introduces PPS materials according to the following topics. First, the molecular weight distribution and morphology of PPS, as well as their reinforced parts, are introduced. Afterward, the topic is focused on the synthesis, process, and blending of PPS. In the next part, this paper investigates the key points regarding PPS as a high-performance polymer, focusing on the aspect of thermal behavior and mechanical properties. Finally, PPS composite applications are emphasized and overviewed from a wide range of aspects.

\section{Introduction}

Generally, polymers can be divided into three categories: thermoplastics, elastomers, and thermosets according to their chemical structure and physical behaviors. The thermoplastics, with linear or branched macromolecules, can be re-melted back into a liquid, whereas elastomers and thermoset always remain in a permanent solid-state due to the molecular structure of their crosslinked network. Moreover, thermosets have a structure with very high crosslinking densities, and their molecular networks will only break at high temperatures. ${ }^{[1]}$ As a matter of fact, many researchers pay much more attention to thermoplastic polymers, especially high-performance polymers with excellent thermal and mechanical properties. Figure 1 shows the schematic pyramid distribution of low- to high-performance amorphous and semicrystalline polymers corresponding to their

Dr. P. Zuo, Prof. A. Tcharkhtchi, Dr. M. Shirinbayan, Dr. J. Fitoussi Arts et Métiers ParisTech

PIMM—UMR CNRS 8006, 151 Boulevard de l'Hôpital, 75013 Paris, France E-mail:2015-1027@ensam.eu

Prof. F. Bakir

Arts et Métiers ParisTech

Dynfluid

151 Boulevard de l'Hôpital, 75013 Paris, France cost. This pyramid provides the information of common thermoplastic materials consisting of three categories (common, mid-range, and high-performance polymers) according to thermal and chemical as well as mechanical properties. Additionally, Table 1 exhibits some parameters of certain high-performance polymers with high resistant-temperatures.

It is widely acknowledged that among a wide range of high-performance polymers, those containing aromatic units, such as poly(ether ether ketone) (PEEK), poly(ether sulfone) (PES), and poly(phenylene sulfide) (PPS), have attracted much attention in the past several decades. In particular, PPS, as one of these polymers, is widely used as a high strength/high temperature engineering thermoplastic for applications such as molding resins, organic fibers, and matrices for thermoplastic composites. Additionally, PPS is commonly and widely used as an engineering polymer with a unique combination of excellent environmental and mechanical as well as thermal properties. In addition, it is applied in a wide range including electronics and electrical appliances, automobiles, precision instruments, chemical sectors, and aerospace fields. ${ }^{[2-15]}$ More intensively, glass fiber or carbon fiber reinforced PPS composites are also popularly used in the automobile, aerospace, and other widespread industrial sectors. ${ }^{[16-35]}$ In particular, PPS and their reinforced parts are capable of enduring high temperatures and resisting well under mechanical loading in some special environmental conditions.

PPS, a semicrystalline polymer with repeated thiophenyl units, has high thermal oxidation and chemical resistance. It has advantages of good toughness, low density, high abrasion resistance, and high chemical as well as thermal stability comparable to other high-performance engineering resins, such as polyimide, polyarylester, and polyetheretherketone. ${ }^{[36-38]}$ Furthermore, PPS, as a high-performance polymer, has better comprehensive mechanical properties than common or middle range polymers such as polypropylene, polyamide, and UHMWPE according to the cost/performance characteristics. ${ }^{[39-41]}$

Comparatively, PEEK is also one of the most promising alternative materials, but it still has some drawbacks such as weak adhesive properties. ${ }^{[42]}$ Moreover, PEEK has a relatively high price when compared with most other polymers and it is 


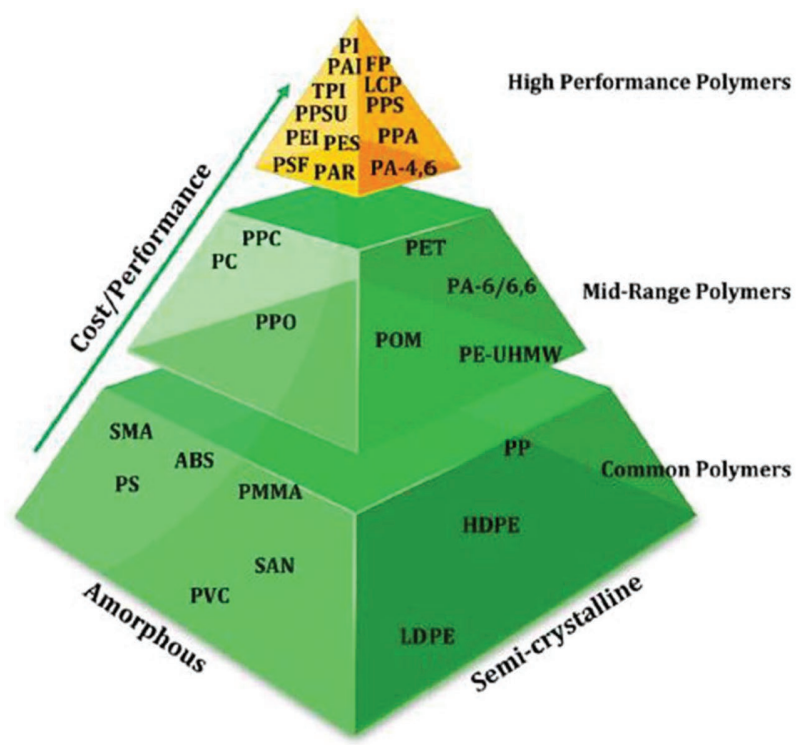

Figure 1. The pyramid graphic of common thermoplastic materials. Note: polyamide (PA), polyamide Imide (PAI), thermoplastic polyimide (TPI), polyphenylene sulfone (PPSU), polyether-imide (PEI), polyethersulfone (PES), polysulfone (PSF), polyaromatic (PAR), fluoropolymers (FP), liquid crystal polymers (LCP), polyphenylene sulfide (PPS), polyphthalamide (PPA), polyamide-4.6 (PA-4.6), polyphthalate carbonate (PPC), polycarbonate (PC), polyphenylene oxide (PPO), polyethylene terephthalate (PET), polyamide-6/6.6 (PA-6/6.6), polyoxymethylene (POM), ultrahigh molecular weight polyethylene (PE-UHMW), styrene maleic anhydride (SMA), acrylonitrile butadiene styrene (ABS), polystyrene (PS), polymethyl methacrylate (PMMA), styrene acrylonitrile (SAN), polyvinyl chloride (PVC), polypropylene (PP), high-density polyethylene (HDPE), low-density polyethylene (LDPE). Adapted with permission. ${ }^{[244]}$ Copyright 2018, Elsevier Science Ltd.

insoluble in industrial solvents. ${ }^{[43-45]}$ It also has some disadvantages such as difficulties regarding synthesis and complex processing conditions. ${ }^{[46-49]}$

Furthermore, considering an epoxy thermoset, it can be widely used as coating, adhesives as well as electric encapsulates, etc. However, epoxy materials have obvious disadvantages such as brittleness due to an intrinsically high degree of crosslinking. ${ }^{[50]}$ Additionally, it has some shortcomings,

Table 1. Some high-temperature resistant thermoplastic polymers. Adapted with permission. ${ }^{[24]}$ Copyright 2018, Elsevier.

\begin{tabular}{lcccc}
\hline Abbreviation & Polymer & $\begin{array}{c}T_{\mathrm{g}} \\
{\left[{ }^{\circ} \mathrm{C}\right]}\end{array}$ & $\begin{array}{c}\text { Continuous } \\
\text { temperature of usage } \\
{\left[{ }^{\circ} \mathrm{C}\right]}\end{array}$ & $\begin{array}{c}\text { Heat deflection } \\
\text { temperature } \\
{\left[{ }^{\circ} \mathrm{C}\right]}\end{array}$ \\
\hline PAI & Polyamide-Imide & 275 & 250 & 279 \\
$\mathrm{PI}$ & Polyimide & 250 & 288 & 246 \\
$\mathrm{PES}$ & Polyethersulfone & 224 & $177-204$ & $204-238$ \\
PEI & Polyetherimide & 213 & $177-204$ & $199-216$ \\
PSF & Polysulfone & 190 & $149-171$ & $171-182$ \\
PEEK & Polyetheretherketone & 143 & $204-232$ & $177-321$ \\
PPA & Polyphthalamide & 134 & $204-232$ & $277-285$ \\
PPS & Polyphenylene sulfide & 92 & $204-232$ & $149-288$ \\
\hline
\end{tabular}


such as the inherently low fracture toughness and poor resistance to fracture as well as relatively low mechanical properties. ${ }^{[51,52]}$

Moreover, polyimide (PI) is widely used in microelectronics and aerospace fields due to its comprehensively excellent properties. ${ }^{[33,54]}$ However, PI polymer materials still encounter problems such as difficult processing and high cost.

In addition, UHMWPE is a good choice in applications that require wear resistance and low friction as well as toughness. However, as we know, it is very difficult to directly process UHMWPE due to its very high viscosity. ${ }^{[55,56]}$

In addition to these resins, there are also thermosetting bismaleimide (BMI) resins, which can be applied for advanced polymer composites. ${ }^{[57,58]}$ However, BMI resin also suffers from inherent brittleness because of its highly crosslinked structures, and some microcracks are easily generated and propagated under friction stress. This is an obvious drawback which needs to be overcome when these resins used. ${ }^{[59]}$

PF (phenol-formaldehyde) resins and their reinforced materials can also resist harsh thermal conditions, they can be used as carbon-mineral materials by blending with other substances and they also have other applications ${ }^{[60-62]}$; however, researchers should also consider their adhesive and toughness properties during applications.

Additionally, the study of Cyanate resin (CE) should be focused on improvement of its fracture toughness and the applied temperatures as well as its comprehensive properties, especially in terms of mechanics. ${ }^{[63-65]}$

All of the polymers are widely used in various industrial sectors. However, it should be mentioned that, considering the performance and cost of these mentioned materials, it seems very necessary to develop the PPS materials in different ways because PPS materials have excellent comprehensive properties and their price is appropriate when their performance is taken into account.

\section{PPS Materials}

\subsection{Overview of PPS}

Poly-phenylene sulfide (PPS) is a polymer consisting of aromatic rings linked with sulfides, and its chemical formula is shown in Figure 2. Additionally, FTIR results of PPS in Figure 3 give detailed information concerning the chemical bonds of the PPS polymer chain.

According to previous reports, PPS was obtained by the polycondensation polymerization method. Macallum synthesized phenylene sulfide polymers from the melt reaction of p-dichlorobenzene with alkali and alkaline earth metal sulfides catalyzed by sulfur. ${ }^{[66]}$ The reaction occurred at approximately $300{ }^{\circ} \mathrm{C}$ under a certain pressure together with the solid-liquid phases. Furthermore, the main work was based on the condensation of p-dichlorobenzene with sodium carbonate and sulfur. It is shown in Figure 4.

The detailed mechanism of the Macallum polymerization reaction was proposed by Lenz and other coworkers. ${ }^{[67-69]}$ They proposed several steps concerning this mechanism as follows:

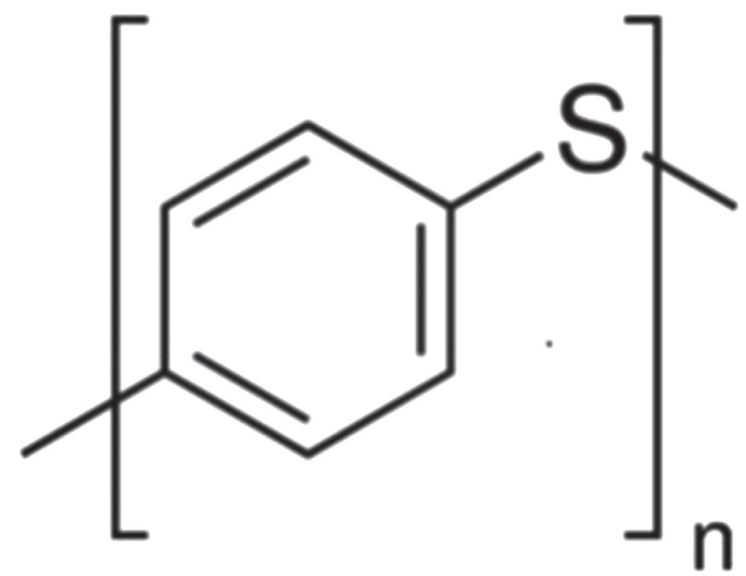

Figure 2. Chemical structure of PPS.

The reaction can be resumed as the following equations:

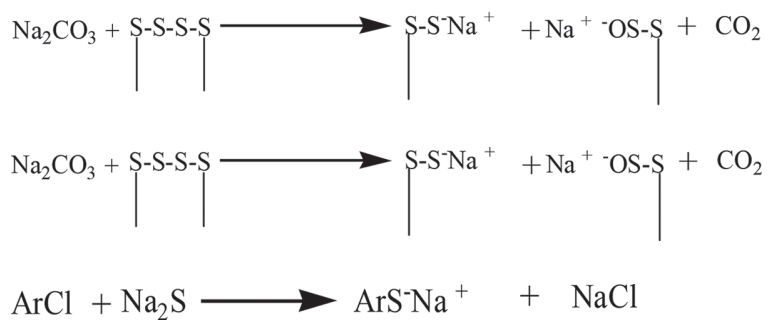

As a conclusion, the following comments are outlined:

- The reaction would start by the formation of polysulfide through a series of nucleophilic substitution types of oxidation-reduction reactions between $\mathrm{Na}_{2} \mathrm{CO}_{3}$ and sulfur.

- Initiation of the polymerization would occur through radical attack by sulfur on the aromatic ring to form a polysulfide side chain.

- Propagation of the reaction would result from successive nucleophilic substitutions by sulfide and thiophenoxide anions on the haloaryl sulfides.

Moreover, the commercial grades of PPS were first introduced by Phillips Petroleum Company in the 1960s under the trade name "Ryton." In detail, they produced two types: one kind is called a thermoplastic branched polymer with a very high

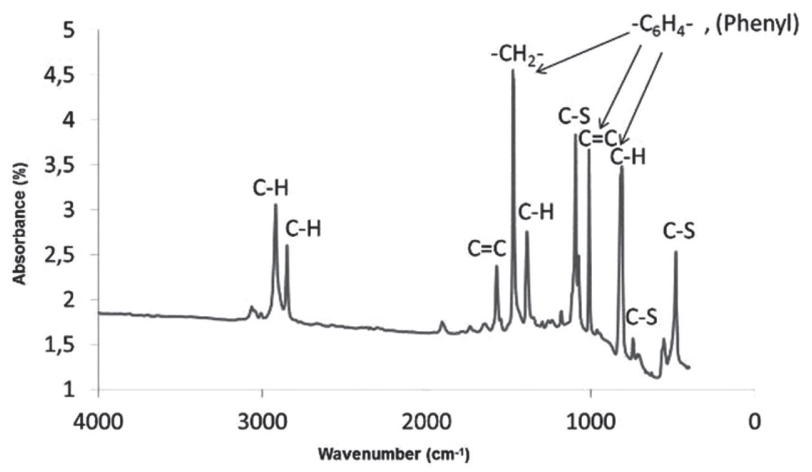

Figure 3. FTIR spectrum results from transmission mode of PPS. 


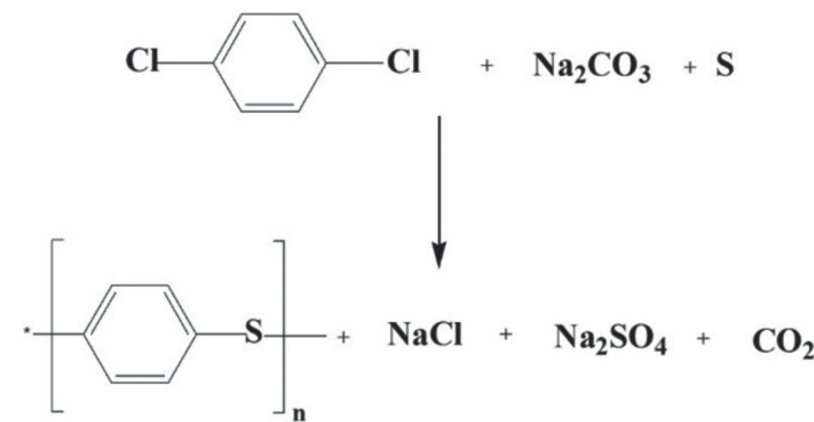

Figure 4. Synthesis of PPS. Adapted with permission. ${ }^{[66]}$ Copyright 1948 , American Chemical Society.

viscosity, which was processed by PTFE-type processes, while the other one is an initial linear polymer, which could be processed by compressing molding that is laminated with glass fiber. ${ }^{[70]}$

\subsection{Molecular Weight of Thermoplastic PPS}

There are two types of PPS: thermoplastic branched PPS with high viscosity and linear PPS polymer. Due to the high melting point $\left(T_{\mathrm{m}}=285^{\circ} \mathrm{C}\right)$ and high dissolution temperature $\left(>200^{\circ} \mathrm{C}\right)$ of PPS in 1-chloronaphthalene (solvent), it is difficult to characterize the molecular distribution and rheological properties in the molten state. However, it tends to be facilitated with the development of high temperature gel permeation chromatography (GPC) technology. Stacy et al. ${ }^{[71]}$ measured the molecular weight distribution of PPS by high-temperature GPC. In their research, they used the Mark-Houwink-Sakurada (MHS) equation (see Equation (4)) to explain the relation of $[\eta]$ (intrinsic viscosity) and $M$ (molecular weight) and gave the values of the constants $K\left(8.91 \times 10^{5}\right)$ and $a(0.747)$ for PPS.

$[\eta]=K M^{a}$

From other research reports, they listed the weight average molecular weight $\left(\bar{M}_{w}\right)$ and the number-average $\left(\bar{M}_{n}\right)$ of PPS from different commercial suppliers (see Table 2). ${ }^{[72]}$

In addition, the report in ref. [73] provided an interesting solution to determine the molecular weight distribution of PPS by the following equations:

$a_{\mathrm{T}}=\frac{\eta_{0}}{\eta_{\text {inf }}}\left(\frac{T_{0}}{T}\right)\left(\frac{L_{0}}{L}\right)$

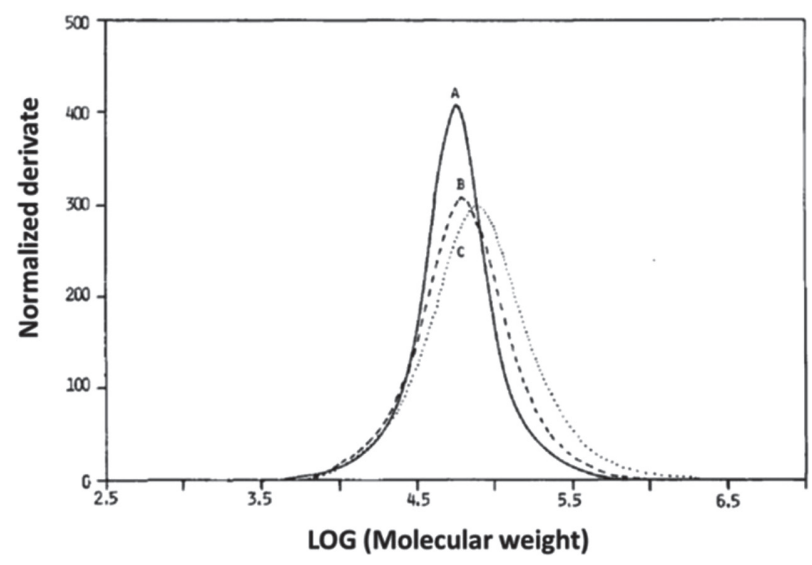

Figure 5. Differential molecular weight distribution curves obtained from dynamic melt viscosity using exact for PPS resin: $A,-)$ virgin; $B,-)$ preheated in air for $30 \mathrm{~min}$;,$\cdots$, preheated in air for $60 \mathrm{~min}$. Adapted with permission. ${ }^{[73]}$ Copyright 1990, Wiley-VCH.

$\eta_{0}=2.06 \bar{M}_{w}^{4.68} 10^{-20}$

where $\eta_{0}$ is the zero-shear viscosity at $\mathrm{T}$ (temperature), $\eta_{\text {inf }}$ is the zero-shear viscosity at the reference temperature $\left(315^{\circ} \mathrm{C}\right.$, the processing temperature of PPS), $L$ is the density, $a_{\mathrm{T}}$ is the shifted factor, $T_{0}$ is the reference temperature $\left(315^{\circ} \mathrm{C}\right)$ and $L_{0}$ is the density at the reference temperature $\left(315^{\circ} \mathrm{C}\right)$. The molecular distribution for thermal-aged PPS is shown in Figure 5. From this Figure, one can note the evolution of the molecular weight distribution of thermal-aged PPS with the time of aging increasing after 30 and $60 \mathrm{~min}$ of heating at $315^{\circ} \mathrm{C}$.

\subsection{Morphology of PPS}

PPS is a semicrystalline thermoplastic polymer and similar to all semicrystalline polymers, its morphology consists of amorphous and crystalline phases. ${ }^{[74]}$ In this section, we discuss the morphology of PPS from the following seven parts: 1) formation of the crystalline phase and spherulites, 2) kinetics of crystallization and kinetic models, 3) effect of the nucleating agent and thermal history (e.g., curing or annealing), 4) effect of fibers in the case of composites, 5) trans-crystallization, and 6) the relation between the crystalline phase and mechanical properties, as well as 7) thermal treatment effect on crystallization.
Table 2. Molecular weight parameters of PPS samples. Adapted with permission. ${ }^{[72]}$ Copyright 1988, Elsevier.

\begin{tabular}{|c|c|c|c|c|c|c|c|}
\hline Sample & Supplier & $\begin{array}{c}\bar{M}_{w} \times 10^{3 \mathrm{~b})} \\
{\left[\mathrm{g} \mathrm{mol}^{-1}\right]}\end{array}$ & $\begin{array}{c}\bar{M}_{n} \times 10^{3 \mathrm{~b})} \\
{\left[\mathrm{g} \mathrm{mol}^{-1}\right]}\end{array}$ & $\bar{M}_{w} / \bar{M}_{n}{ }^{a)}$ & $\begin{array}{c}\bar{M}_{w} \times 10^{\left.3^{c}\right)} \\
{\left[\mathrm{g} \mathrm{mol}^{-1}\right]}\end{array}$ & $\begin{array}{c}\bar{M}_{n} \times 10^{\left.3^{c}\right)} \\
{\left[\mathrm{g} \mathrm{mol}^{-1}\right]}\end{array}$ & $\bar{M}_{w} / \bar{M}_{n}{ }^{c)}$ \\
\hline A & Phillips & 18.1 & 2.8 & 6.4 & 22.0 & 15.8 & 1.39 \\
\hline B & Kureha & 35.7 & 2.2 & 16.2 & 39.8 & 20.6 & 1.94 \\
\hline C & Kureha & 46.7 & 2.5 & 18.5 & 50.7 & 26.6 & 1.91 \\
\hline
\end{tabular}

a) Determined in 1-chloronaphthalene at $210^{\circ} \mathrm{C}$; b) Obtained by the modified UV-vis absorption detector method; c) Obtained by the Stacy viscometric detector method.

\subsubsection{Formation of Crystalline Phase and Spherulites}

For the study in this section, the cooling process can be divided into two types: isothermal crystallization and nonisothermal crystallization.

From the aspect of isothermal crystallization, Figure 6 represents the formation of the spherulites under an optical microscope 


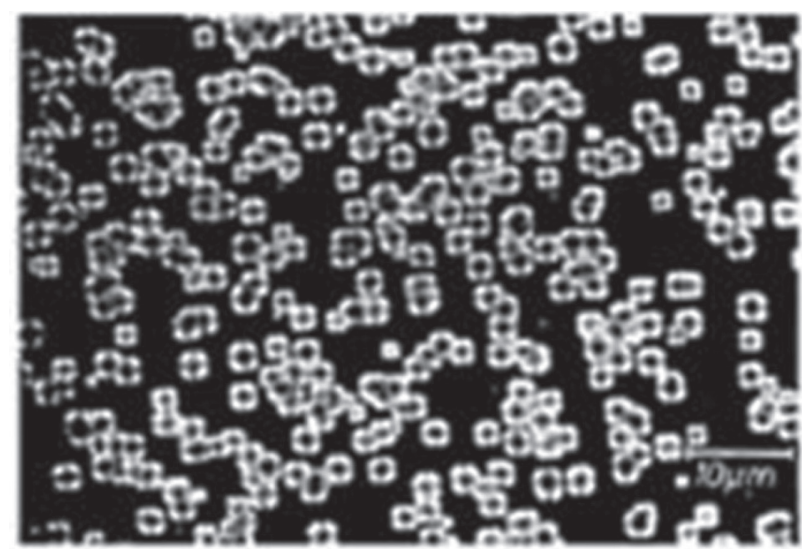

Figure 6. Optical microscopy photo of pure PPS at $T_{\mathrm{c}}=221^{\circ} \mathrm{C}$. Adapted with permission. ${ }^{[75]}$ Copyright 1994, Wiley-VCH. equipped with a heating device. The photo presented in this figure was taken in the stage of the isothermal growth of spherulites with spherical morphology at $221{ }^{\circ} \mathrm{C}$; one can note the typical homogeneous spherulites with a diameter of approximately $2 \mu \mathrm{m}$ at $221^{\circ} \mathrm{C} .^{[75]}$

Furthermore, DSC and polarized light microscopy (PLM) techniques are popularly used to characterize the isothermal crystallization process, not only in the domains of metals but also in polymers and composites domains. Liliana et al. ${ }^{[76]}$ studied the isothermal crystallization behavior of PPS by DSC and PLM techniques. The highest crystallization rate was obtained with isothermal treatment at $268^{\circ} \mathrm{C}$.

From the aspect of nonisothermal crystallization, Lian et al. ${ }^{[7]}$ studied the morphology of the nonisothermal crystallization process for pure PPS which has been shown by the polarized optical microscopy (POM) photos. These photos show (see Figure 7) that the pure PPS presented well developed

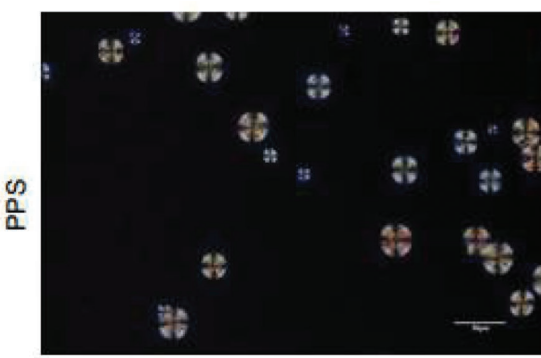

$T=225^{\circ} \mathrm{C}$

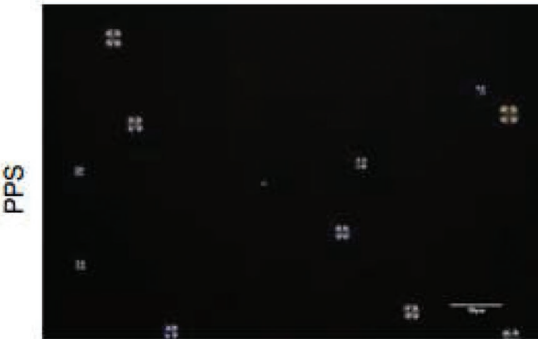

$T=205^{\circ} \mathrm{C}$

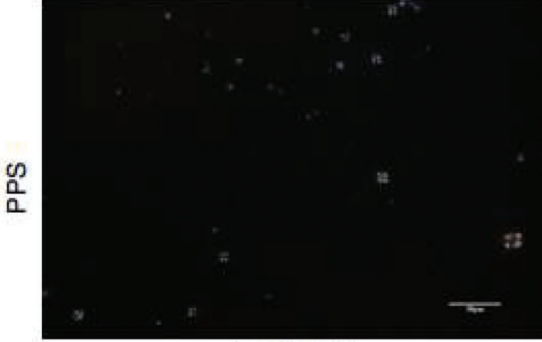

$T=195^{\circ} \mathrm{C}$

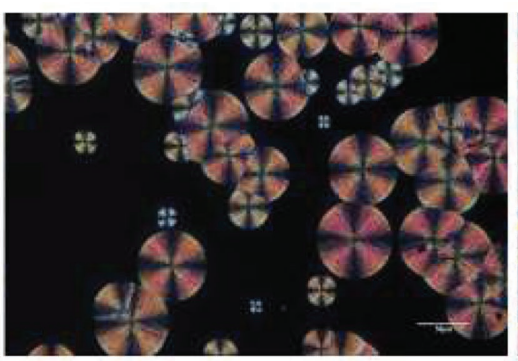

$T=205^{\circ} \mathrm{C}$

(a)

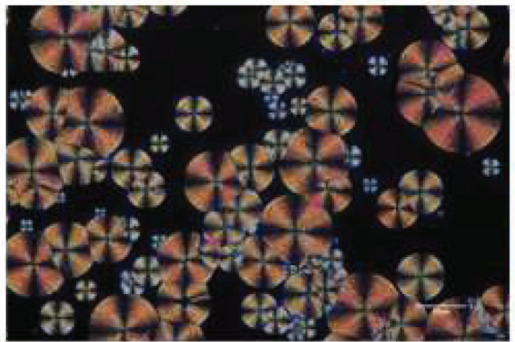

$T=185^{\circ} \mathrm{C}$

(b)

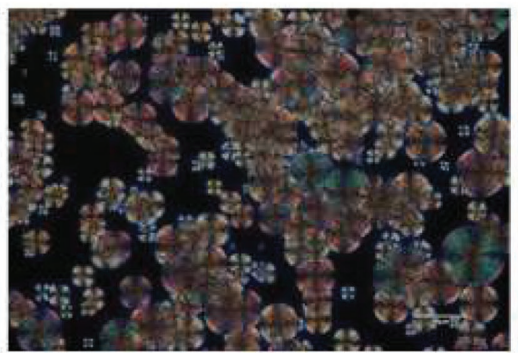

$T=170^{\circ} \mathrm{C}$

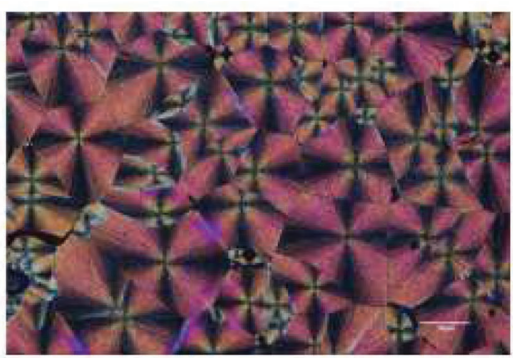

$T=195^{\circ} \mathrm{C}$

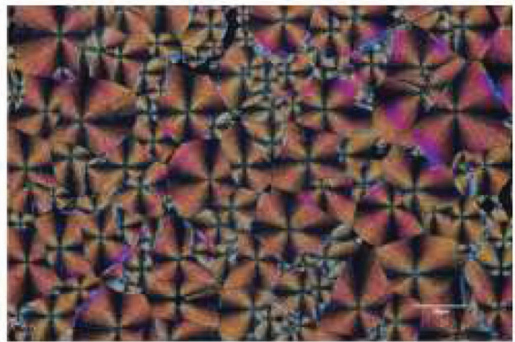

$T=160^{\circ} \mathrm{C}$

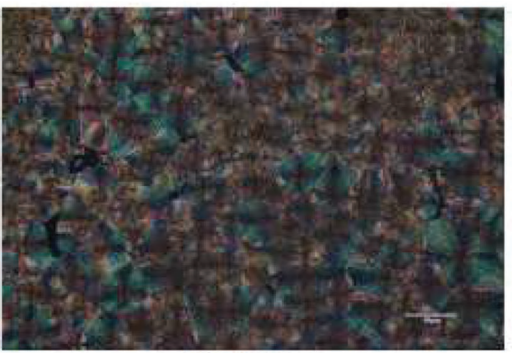

$T=140^{\circ} \mathrm{C}$

(c)

Figure 7. POM images of virgin PPS during nonisothermal crystallization process at a) $5{ }^{\circ} \mathrm{C} \mathrm{min}^{-1}$; b) $20^{\circ} \mathrm{C} \mathrm{min}^{-1}$; c) $30^{\circ} \mathrm{C}$ min ${ }^{-1}$. Adapted with permission. ${ }^{[77]}$ Copyright 2017, Springer. 
spherulites with distinct boundaries. In this work, the authors also studied the effect of the cooling rate on crystallization phenomena. They have performed three different tests at different cooling rates $\left(5,20\right.$, and $\left.30^{\circ} \mathrm{C} \mathrm{min}^{-1}\right)$. One can see different crystallization stages and nucleation as well as growth at different rates of cooling. When the cooling rate was low $\left(5^{\circ} \mathrm{C} \mathrm{min}{ }^{-1}\right)$, the beginning and final stages of crystallization can be observed at the high temperature range $\left(225-195{ }^{\circ} \mathrm{C}\right)$, but at the high cooling rate $\left(30^{\circ} \mathrm{C} \mathrm{min}^{-1}\right)$, crystallization would be seen at the lower temperature range $\left(195-140{ }^{\circ} \mathrm{C}\right)$ under microscopy. In addition, the final spherulites were larger when the cooling rate was lower.

\subsubsection{Kinetics of Crystallization and Kinetic Models}

Some researchers in ref. [78] compared the crystallization kinetics of virgin and solvent treated PPS. The overall crystallization rates were found to be much faster for the solvent-treated PPS than for the virgin neat PPS. Some other investigators compared different polymers: For example, Song et al. ${ }^{[79]}$ studied the crystallization kinetics and nucleating agents for enhancing the crystallization of PPS. The comparison of PPS crystallization rates with those of other polymers indicates that it crystallizes much more slowly than polyethylene or isotactic polypropylene.

Moreover, some kinetic models (e.g., Avrami model) were applied to investigate the crystallization kinetics of PPS. The Avrami model can be used as follows:

$X_{t}=X_{v c r}=1-\exp \left(-k t^{n}\right)$

$\log \left[-\log \left(1-X_{v c r}\right)\right]=\log k+n \log t$

where $X_{t}=X_{v c r}=X_{v c} / X_{v c m a x}$ at time $\mathrm{t}$ is the relative volume fraction of crystallinity, $X_{v c}$ is the volume fraction of crystallinity, $\mathrm{n}$ is the Avrami exponent and $\mathrm{k}$ is a temperature-dependent rate constant.

As seen in Figure 8, a good linear regression implies the Avrami model can be well applied to perform modeling concerning the isothermal crystallization for PPS materials with reinforcement.

\subsubsection{Effect of the Nucleating Agent and Thermal History (e.g., Curing or Annealing)}

Nucleating Agent: In practice, the nucleation may begin on the surface with the nucleation sites such as fillers or additives (e.g., fibers, nanotubes). For example, Jiang et al. ${ }^{[80]}$ prepared a series of composites by mixing PPS with multiwalled carbon nanotubes at 1, 2, and $3 \mathrm{wt} \%$ to investigate the nucleation effect of hydroxyl-purified multiwalled carbon nanotubes in PPS composites. They revealed that the enthalpy $\Delta H_{\mathrm{c}}$ of the composites increased with increasing the amounts of multiwalled carbon nanotubes, whereas the crystallization temperature decreased dramatically in parallel.

Moreover, with the addition of carbon nanofiber in PPS, there was a slight decrease in the crystallization temperature but no significant change in the melting point or the glass transition

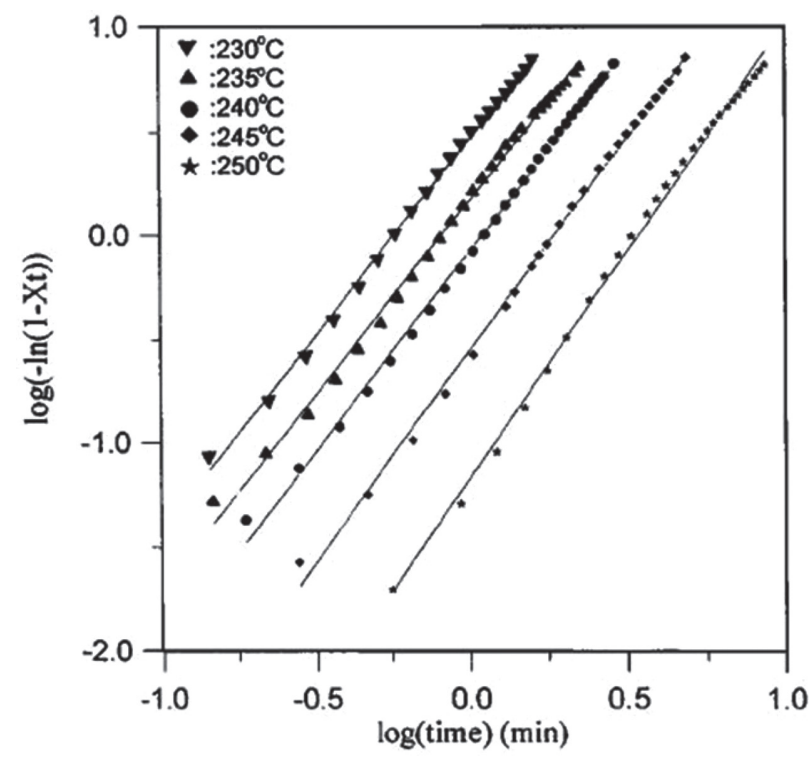

Figure 8. Avrami plots of carbon (10\%)-filled PPS samples crystallized at $230,235,240,245$, and $250^{\circ} \mathrm{C}$. Adapted with permission. ${ }^{[245]}$ Copyright 1995, Wiley-VCH.

temperature. ${ }^{[81]}$ From the results of Figure 9 and Table 3, one can conclude that the higher the proportion of CNF, the lower was the crystallinity. This is mainly due to the propensity of CNF in hindering the orderly arrangement of PPS molecules.

Other additives can also be regarded as a nucleating agent for PPS. For example, ref. [82] reported nanodiamond (ND) as an efficient nucleating agent for PPS, and they clarified that the Avrami equation and Mo method provided a fairly satisfactory description for the nonisothermal crystallization of PPS in both pure and composite forms. Nanodiamond particles can supply a heterogeneous nucleation point for PPS by dramatically improving the crystallization temperature and crystallization rate. In particular, it can be seen the ND particles morphology is spherical or nearly spherical in Figure 10. Moreover, the micrographs show that many particles are aggregated together due to the high instability resulting from the high surface energy and the large surface area of the particle quantity. Comparatively, the morphology of the composite surface tends to be meticulous and smooth after mixing with ND particles.

Thermal History: Thermal history (e.g., curing or annealing) plays an important role during the crystallization process because the thermal history can not only affect the crystallization behavior but can also change the crystal structure. Some commercial PPS treated by thermal curing was studied by Lee et al. ${ }^{[83]}$ and they found an increase of molecular weight due to crosslinking. The reasons can be explained as follows: PPS is a thermoplastic polymer with generally low molecular weight. Some phenomena such as oxidation (or thermal treatment) may create a crosslinked junction between molecular chains; however, the density of crosslinking is not high and the structure is not truly a 3D network. It is indeed the branched macromolecules with a higher molecular weight. They concluded the crosslinking of PPS can significantly affect crystallization behaviors. Lu et al. ${ }^{[84]}$ studied the effects of annealing on the 

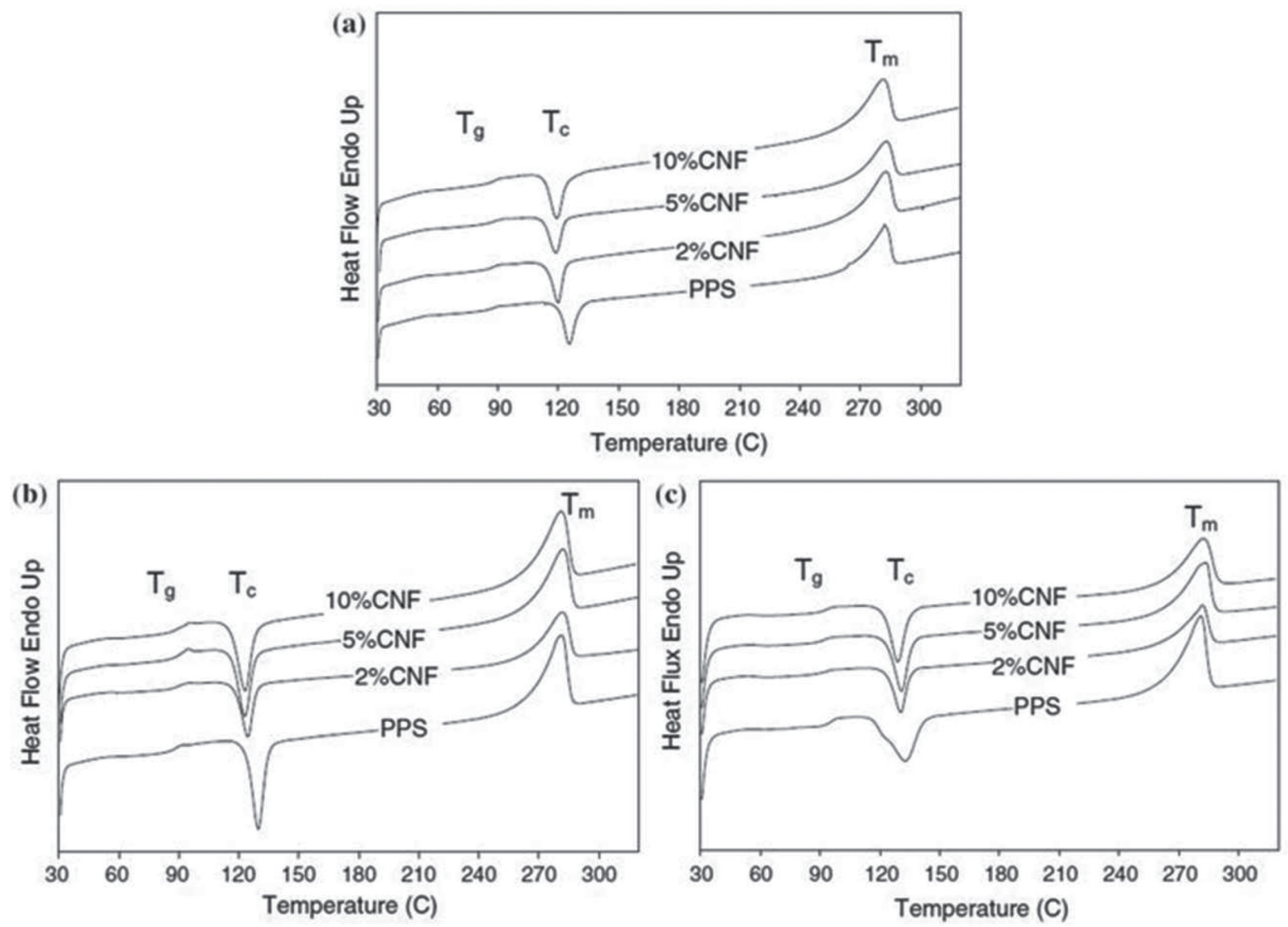

Figure 9. Differential Scanning Calorimetry (DSC) analysis of PPS-CNF composites as a function of heating rate: a) $5^{\circ} \mathrm{C} \mathrm{min}^{-1}$, b) $10^{\circ} \mathrm{C} \mathrm{min}{ }^{-1}$, and c) $20{ }^{\circ} \mathrm{C} \mathrm{min}{ }^{-1}$. CNF proportions corresponding to volume. Adapted with permission. ${ }^{[81]}$ Copyright 2017, Springer.

relaxation behavior and charge trapping in film-processed PPS. DSC results suggested that annealing increased the crystallinity of PPS film. Brady et al. ${ }^{[85]}$ examined the crystallinity of PPS, and they concluded that curing (crosslinking and chain extending)

Table 3. Effect of CNF on the thermal properties from DSC analysis. Adapted with permission. ${ }^{[81]}$ Copyright 2007, Springer Nature.

\begin{tabular}{lccccccc}
\hline Sample & $\begin{array}{c}\text { Heating rate } \\
{\left[{ }^{\circ} \mathrm{C} \mathrm{min}^{-1}\right]}\end{array}$ & $\begin{array}{c}T_{\mathrm{g}} \\
{\left[{ }^{\circ} \mathrm{C}\right]}\end{array}$ & $\begin{array}{c}T_{\mathrm{c}} \\
{\left[{ }^{\circ} \mathrm{C}\right]}\end{array}$ & $\begin{array}{c}T_{\mathrm{m}} \\
{\left[{ }^{\circ} \mathrm{C}\right]}\end{array}$ & $\begin{array}{c}\Delta H_{\mathrm{c}} \\
{\left[\mathrm{J} \mathrm{g}^{-1}\right]}\end{array}$ & $\begin{array}{c}\Delta H_{m} \\
{\left[\mathrm{~g} \mathrm{~g}^{-1}\right]}\end{array}$ & $\begin{array}{c}X_{\mathrm{c}} \\
{[\%]}\end{array}$ \\
\hline PPS & 5 & 83.9 & 125.1 & 281.9 & 39.5 & 59.2 & 16.3 \\
PPS-2\% CNF & & 83.5 & 119.9 & 282.3 & 16.9 & 34.1 & 14.6 \\
PPS-5\% CNF & & 84.5 & 118.3 & 282.1 & 18.6 & 34.0 & 13.6 \\
PPS-10\% CNF & & 84.7 & 120.3 & 281.9 & 17.0 & 29.6 & 11.9 \\
PPS & 10 & 84.8 & 129.5 & 281.0 & 38.8 & 60.0 & 16.7 \\
PPS-2\% CNF & & 85.4 & 124.2 & 281.5 & 23.8 & 42.0 & 15.4 \\
PPS-5\% CNF & & 86.5 & 123.0 & 281.8 & 20.2 & 35.0 & 13.1 \\
PPS-10\% CNF & & 85.9 & 123.8 & 281.5 & 16.5 & 30.0 & 12.7 \\
PPS & 20 & 86.6 & 132.6 & 281.0 & 29.3 & 45.6 & 13.5 \\
PPS-2\% CNF & & 86.4 & 130.6 & 281.8 & 27.8 & 41.9 & 12.0 \\
PPS-5\% CNF & & 86.2 & 130.9 & 282.5 & 19.6 & 33.4 & 12.2 \\
PPS-10\% CNF & & 87.1 & 129.0 & 282.2 & 17.0 & 27.1 & 9.6 \\
\hline
\end{tabular}

the resin by heating in air affected the crystallization ability of the resin. As previously mentioned, because of the thermal treatment, the formation of some crosslinking points in the structure of PPS occurs. The chains around these crosslinking points are less mobile. They may act as nucleating agents which increase the degree of crystallinity. However, high crosslinking density hinders the crystallization. Moreover, the observation of crystalline morphologies by optical microscopy suggests that thermal curing for as little as 1 day contributes to the formation of smaller size crystallinity of spherulites in regard to nontreated pure PPS.

Moreover, ref. [86] studied the effect of thermal history on the crystal structure of PPS. The results showed the dimensions of the crystal lattice were strongly dependent on previous thermal conditions. With the annealing time improving at the fixed temperature, the decrease of lattice $a, b$ led to an increase in lattice density. In this study, the plots of unit cell parameters and the lattice density versus the cold-crystallization temperature are shown in Figure 11. The unit cell parameters $\mathrm{a}$ and $\mathrm{b}$ first showed a decrease 


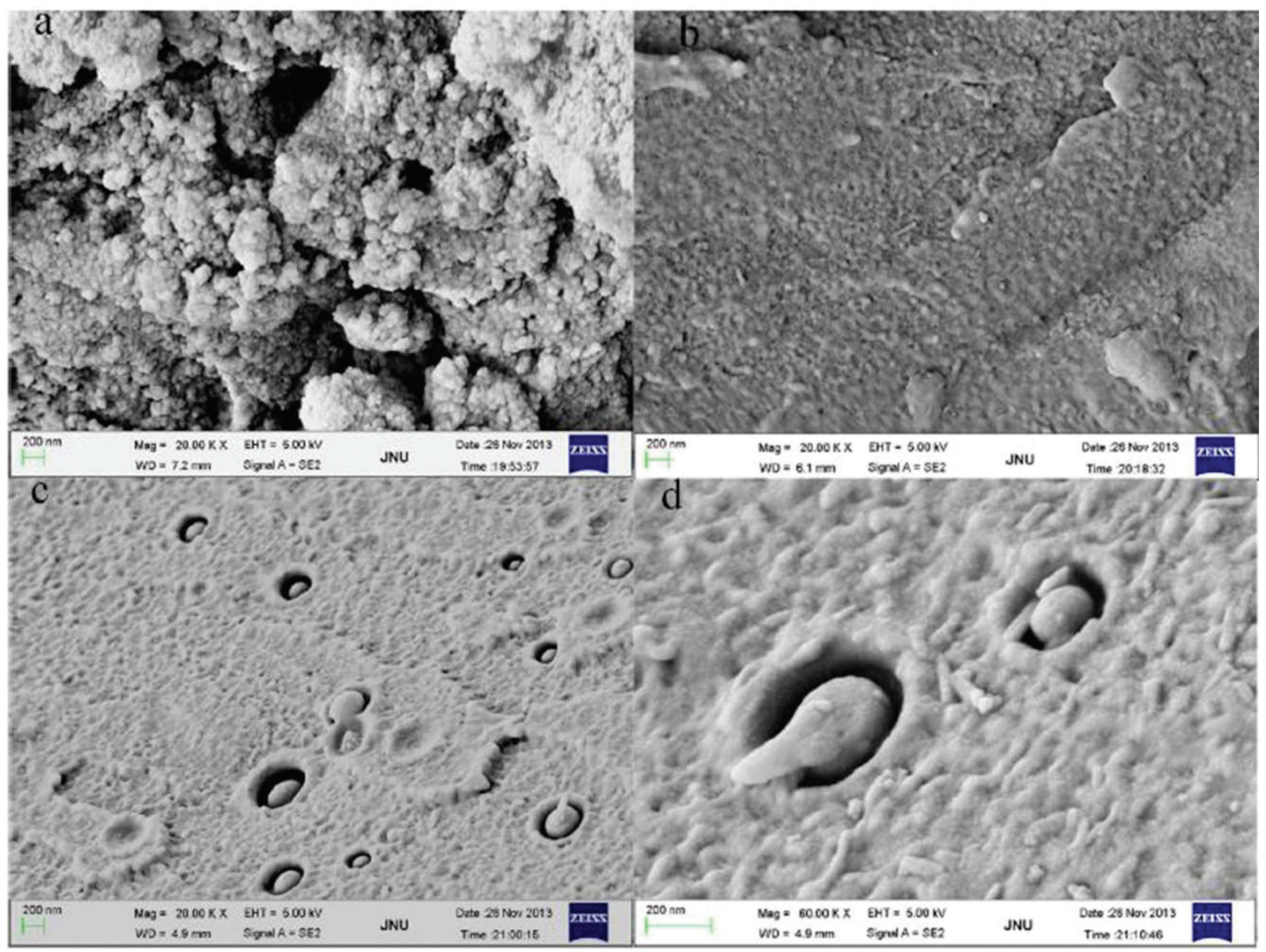

Figure 10. SEM images of: a) nanodiamond; b) PPS; and c,d) PPS/ND. Adapted with permission. ${ }^{[82]}$ Copyright 2014, Elsevier Science Ltd.

with the cold-crystallization temperature increasing, but when the crystallization temperature increased above $245^{\circ} \mathrm{C}$, the unit cell parameters $\mathrm{a}$ and $\mathrm{b}$ varied. The unit cell parameter $\mathrm{c}$ first increased until reaching the cold-crystallization temperature of $245{ }^{\circ} \mathrm{C}$, and then fluctuated. However, the density of PPS crystal increased with crystallization temperature up to $255^{\circ} \mathrm{C}$ and decreased when the temperature was $265{ }^{\circ} \mathrm{C}$. This implies that thermal history can significantly affect the crystal structure.

\subsubsection{Effect of Fibers in the Case of Composites}

Generally, the thermal history can modify the extent and nature of crystallization for any thermoplastic polymers. However, in the case of composites that are reinforced with fibers, the morphology can also be affected by the fibers. For example, the report of ${ }^{[87]}$ studied the isothermal crystallization from the melt of unreinforced PPS and of model carbon and aramid as well as glass fiber reinforced PPS composites. The result indicated that the influence of fibers on PPS crystallization was decided not only by surface treatment but also by fibers themselves. Additionally, as we discussed above, the fibers can provide the nucleation site for crystallization and this may have some effect on crystallization process.

\subsubsection{Trans-Crystallization}

Interestingly, some trans-crystallization phenomena can be observed in some composites during cooling and formation of crystalline morphology. First, it should be noted that the black line is the fiber, and trans-crystallization starts from this place situated around the fiber. In detail, it can be concluded as follows: the surface of the fibers provides the nucleation sites, which could form the spherulites around these nucleation sites (see Figure 12). One can note the trans-crystalline layer grew over the whole embedded fiber length and subsequently the layer thickness increased. ${ }^{[88]}$

\subsubsection{The Relation between the Crystalline Phase and Mechanical Properties}

As we know, the crystallization behaviors can also directly affect mechanical properties. For example, Lu et al. ${ }^{[89]}$ studied the effect of the crystallinity on impact properties and they found the relationship as follows: the impact strength of PPS blends increased with the decrease in crystallinity. Moreover, fracture toughness was studied by Nishihata et al. ${ }^{[0]}$ They used the linear PPS, heat-treated PPS and branched PPS as specimens. 

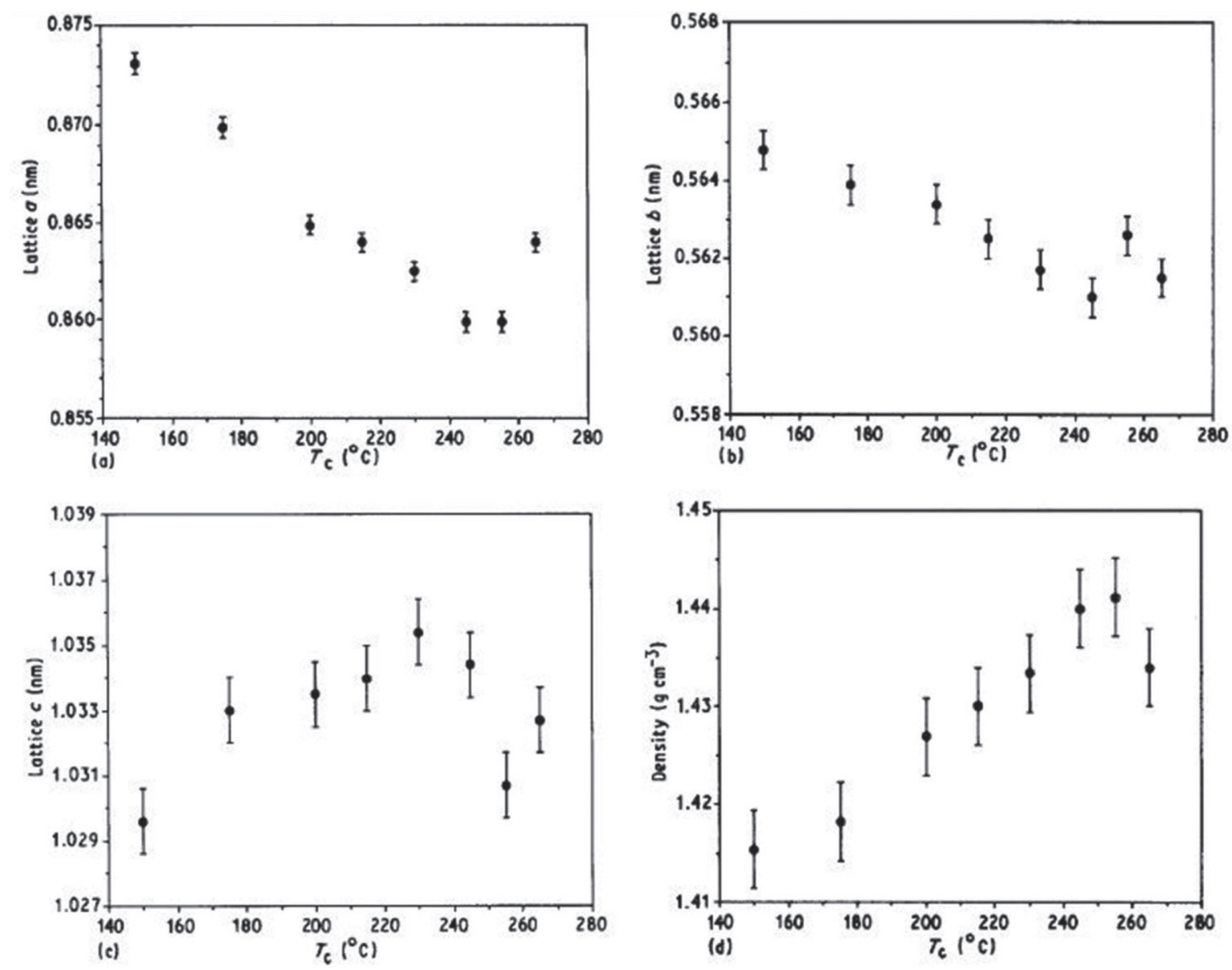

Figure 11. Lattice parameters versus cold-crystallization temperature: a) unit cell parameter; b) unit cell parameter; c) unit cell parameter; d) lattice density. Adapted with permission. ${ }^{[86]}$ Copyright 1992, Springer.

The results showed that the fracture toughness of linear PPS was superior to that of heat-treated PPS and branched PPS, and the fracture toughness was affected by the crystallinity. Nevertheless, we should mention that in this reference, they used

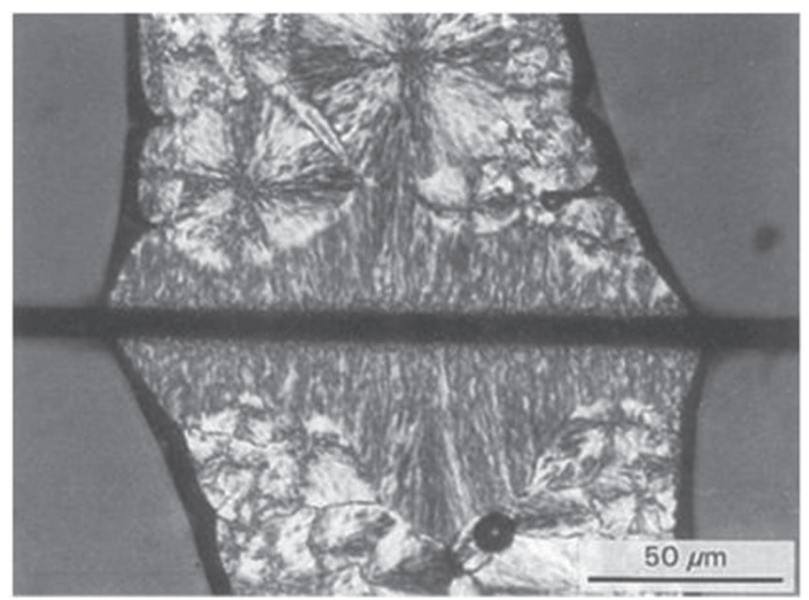

Figure 12. Typical PPS trans-crystallization morphology around T700S fiber in fiber pull-out samples. Adapted with permission. ${ }^{[88]}$ Copyright 1995, Springer. different kinds of PPS (for example several types of linear PPS), and the effect of crystallinity on fracture toughness cannot be concluded by a monotonic tendency.

\subsubsection{Thermal Treatment Effect on Crystallization}

Wide angle X-ray diffraction (WXRD) methodology was used by Liu et al. ${ }^{[91]}$ and they evaluated the crystallization behavior of PPS during processing and thermal treatment. One can see that major diffraction peaks at $18.7,20.7,25.6$, and $27.7^{\circ}$ can refer to the index of reflections on the (110), (200), (112), and (211) lattices' planes of the orthorhombic structure (see Figure 13a). Additionally, from Figure 13b, one can conclude that the thermal treatment can lead to an increase in the intensity peaks. This mainly indicates that an improvement of crystal perfection occurs due to the molecular chain rearrangement arising from the annealing or thermal treatment process.

\section{PPS Processing}

The melting point of PPS is relatively high $\left(285^{\circ} \mathrm{C}\right)$, and PPS molding takes place at high temperature. ${ }^{[92-101]}$ As a 

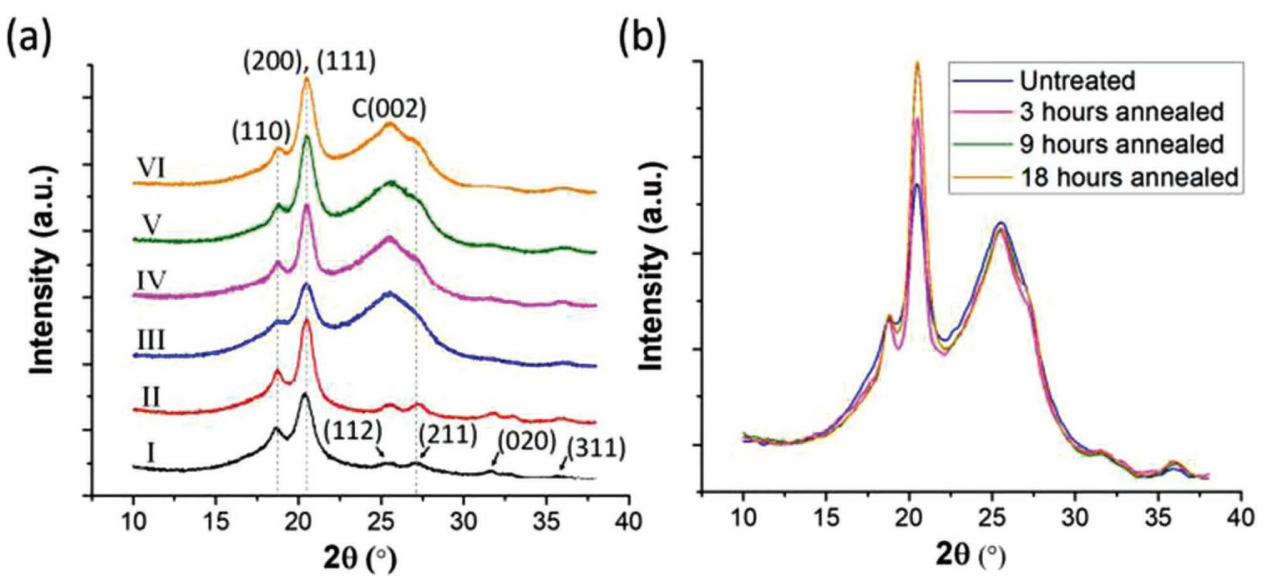

Figure 13. a) WAXD patterns of neat PPS and carbon fiber reinforced PPS: I. injection molded neat PPS, no heat treatment; II. Injection molded neat PPS, annealed for $3 \mathrm{~h}$ at $250^{\circ} \mathrm{C}$; III. AM PPS/CF (50 wt\%), no heat treatment; IV. AM PPS/CF (50 wt\%), annealed for $3 \mathrm{~h}$ at $250{ }^{\circ} \mathrm{C} ; \mathrm{V}$. AM PPS/CF ( $50 \mathrm{wt} \%$ ), annealed for $9 \mathrm{~h}$ at $250^{\circ} \mathrm{C}$; VI. AM PPS/CF (50 wt\%), annealed for $18 \mathrm{~h}$ at $250^{\circ} \mathrm{C}$. b) WAXD patterns of AM PPS/CF (50 wt\%) with different thermal histories. Adapted with permission. ${ }^{[91]}$ Copyright 2018, Elsevier Science Ltd.

result, in order to avoid the degradation of the polymer, it is highly desirable to have a process for molding PPS during a minimum of molding time. The general process for producing PPS containing mixtures was disclosed in ref. [102] This process could be described as follows: PPS is first mixed with the selected filler and subsequently they were molded in a compressive way to form a part of a needed shape. This part is then freely sintered by being subjected to a gradually increasing temperature in an oven and cured for some time. After the curing process, the part is cooled and is ready for utilization. Other related processes to produce PPSbased materials (film, fibers) can be found in the patents of refs. [103,104] Virgin PPS presents difficulties in injection molding. Its high fluidity in the molten state will require the usage of a shutter nozzle and to cure sealing of the mold. Moreover, the patent of ref. [105] introduced a sheet formed by randomly dispersing and accumulating PPS filaments. The filaments drawn by a high-velocity air stream were formed directly into a sheet. This produced sheet could be used as industrial filters and heat insulating materials due to its outstanding chemical and thermal properties.

Additionally, the properties of injection molded PPS thermoplastics are shown in Table $4^{[70]}$ :

\section{Blending}

With the development of society and the economy, more polymers have increasingly been synthesized and applied in different domains. However, they are not sufficient to meet the requirements of the growing demand of polymers with different properties (e.g., miscible or immiscible, ${ }^{[106-110]}$ electrical, ${ }^{[111-117]}$ thermal, ${ }^{[40,117-121]}$ mechanical, ${ }^{[40,111,122-126]}$ and tribological properties $\left.{ }^{[23,28,127-132]}\right)$. Thus, blends and composites are compounded to improve the utilization of different polymers. In particular, in this section, we pay more prominent attention to the polymer blends, especially those with the compositions containing PPS. [130,131,133-136]
As mentioned above, neat PPS is rather brittle and has low impact strength as well as difficulties in injection molding. Thus, many approaches have been proposed to overcome these disadvantages of PPS. To modify PPS by physical blending or alloying with other polymers or with other reinforcement materials is the most common and widespread method in industrial and academic domains currently. ${ }^{[28,137-145]}$

Thus, in this section, we introduce the modifications according to the following three aspects: 1) PPS blending with other polymers; 2) PPS mixing with nanotubes at the nanoscale range; and 3) other additives in blending.

\subsection{PPS Blending with Other Polymers}

There is a wide range in the literature regarding discussions about blending PPS with other polymers. For example, Lim et al. ${ }^{146]}$ investigated the thermal behavior and phase morphology of binary blends of PPS with polycarbonate(PC), and they found the melt viscosity of PPS/PC blends was largely

Table 4. Properties of injection molded PPS. Adapted with permission. ${ }^{[70]}$ Copyright 2013, Heinemann.

\begin{tabular}{lccc}
\hline Property & Units & PPS & $\begin{array}{c}\text { PPS/glass fiber } \\
{[60 / 40]}\end{array}$ \\
\hline Specific gravity & & 1.35 & 1.65 \\
Tensile strength & $\mathrm{MPa}$ & $64-77$ & 150 \\
$21{ }^{\circ} \mathrm{C}$ & $\mathrm{MPa}$ & 33 & 33 \\
$204^{\circ} \mathrm{C}$ & $\mathrm{MPa}$ & 4200 & 15500 \\
Flexural modulus $21^{\circ} \mathrm{C}$ & $\%$ & 3 & $2-3$ \\
Elongation at break & & 3.1 & 3.8 \\
Dielectric constant $\left[10^{3}-10^{6} \mathrm{~Hz}\right]$ & & 0.004 & 0.0037 \\
Dissipation factor $[1 \mathrm{kHz}]$ & $\Omega \mathrm{cm}$ & $2.5 \times 10^{16}$ & \\
Volume resistivity & $\%$ & $<0.02$ & $<0.05$ \\
Water absorption & & & \\
\hline
\end{tabular}


decreased when the PC was added to the PPS polymer. Moreover, the melting behavior of PPS and its blends with PSF (polysulfone) and PEK-C (polyetherketone with phthalidydene groups) was reported in ref. [141] The results showed the melt temperature $T_{\mathrm{m}}$ and melt time $t_{\mathrm{m}}$ increased, and the intensities of the lower melting peaks of PPS increased. These phenomena could be attributed to the structure of PPS which impedes the formation of upper melting crystals and the transformation of lower melting crystals into upper melting crystals.

In addition, Oyama et al. ${ }^{[147]}$ studied the high-performance reactive blends containing PPS. They clarified that the reactive PPS blends showed good thermal stability up to $400{ }^{\circ} \mathrm{C}$.

Furthermore, the crystallization behaviors of polymers blending with PPS are a primary concern of many researchers. Shingankuli et al. ${ }^{[148]}$ explored the thermal and crystallization behavior of engineering polyblends (glass reinforced PPS with polyethylene terephthalate). They revealed that the degree of crystallinity of PPS was reduced, whereas that of PET was increased due to blending. The crystalline morphologies of isothermally and nonisothermally crystallized PPS and their blends with PA66 were investigated. ${ }^{[149]}$ The results exhibited that the presence of PA66 remarkably affected the crystallization process of PPS. Moreover, the nonisothermal crystallization behavior and kinetics of the PPS/polycarbonate blend were studied in the report of, ${ }^{[150]}$ and showed that the crystallization temperature of the PPS component in the blend decreased with the increasing of PC contents. In addition, some researchers ${ }^{[131]}$ prepared the PPS/polyvinylidene fluoride(PVDF) polymer alloys by melt blending, and the results indicated that the addition of PVDF can accelerate the crystallization of PPS and improve the thermal stability of PPS/PVDF alloys. The multiple melting behaviors of PPS blends with Polyamide 6 were also studied, ${ }^{[151]}$ and the results suggested that PA 6 can accelerate the cold-crystallization of amorphous PPS. The researchers of ${ }^{[152]}$ also investigated the through-thickness distribution of liquid crystalline polymer (LCP) in PPS/LCP blends. They concluded that a nonuniform distribution of LCP in the PPS-rich region occurred.

In addition, the mechanical properties of these blending polymers with PPS also attracted some attention from the investigators. The dynamic mechanical behavior of blending PPS with acetylene-terminated sulfone was studied by Zeng et al. ${ }^{[153]}$ They demonstrated that the flexural modulus and interlaminar shear strength (ILSS) of continuous unidirectional carbon fiber composites with a blended matrix of ESF/PPS $=10 / 90$ were obviously higher than those of composites with the pure PPS matrix. Similarly, the microdispersion of polyphenylene ether in PPS/PPE alloy can also affect the mechanical behaviors. ${ }^{[143]}$ In this study, it showed that the weld strength of PPS/SG/ PPE was found to be significantly decreased because of the increasing particle diameter.

In addition, styrene-b-ethylene/butylene- $b$-styrene triblock copolymer (SEBS) and maleic anhydride grafted SEBS (sebsg-MA) for the blends of polyphenylene sulfide/nylon 66(PPS/ PA 66) were prepared by Tang et al. ${ }^{[140]}$ They demonstrated that the addition of elastomers remarkably increased the toughness of PPS/PA66 blends. Wang et al. ${ }^{[154]}$ explored the kinetic and thermodynamic behavior of water absorption in unidirectional fiber reinforced composites by blending PES and PPS. The results revealed that PPS reduced water absorption by weakening the polarity of benzene and forming a compact structure by crystallization.

\subsection{PPS Mixing with Nanotubes at the Nanoscale Range}

From the aspect of mixing with carbon nanotubes under nanoscale conditions, there are also considerable research reports. For example, Yu et al. ${ }^{[155]}$ fabricated multiwall carbon nanotube (MWCNT) reinforced PPS nanocomposites through melt compounding. The results showed that the incorporation of carbon nanotubes into PPS had a remarkable increase in the aspect of thermal stability for this nanocomposite. Similarly, PPS/MWCNT composites through melting compounds were prepared and investigated by Yang et al. ${ }^{[156]}$ and they concluded that the concentration of multiwall nanotubes can have some effects on the structure and chain mobility of the prepared composites. More intensively, they found a significant increase of $T_{\mathrm{g}}$ and the storage modulus when multinanotubes were added in PPS. Moreover, the research in ref. ${ }^{[157]}$ studied PPS/multiwall nanotube composites from the perspective of physical aspects. The report revealed that the multiwall nanotube was fully dispersed in the PPS matrix, especially at low loading levels due to their good affinity. The presence of multiwall nanotubes can make a positive contribution to both the tensile properties and dynamic thermal mechanical properties. In addition, SWCNT buckypaper (BP) reinforced-PPS composite laminates were manufactured by Pascual et al. ${ }^{[158]}$ through hot-press processing. The TGA analysis demonstrated a remarkable improvement in the degradation temperature of the polymers by the incorporation of the BP. These authors also investigated the mechanical properties of carbon nanotube/PPS composites incorporating polyetherimide and inorganic fullerene-like nanoparticles, and the results revealed that mechanical properties were enhanced in aspects of stiffness and strength by the addition of both nanofillers. Moreover, MWCNT reinforced PPS nanocomposites were fabricated by Yu et al. ${ }^{[159]}$ through melt compounding, and they found both thermal and mechanical properties showed an increase with the addition of CNT friction. As the results show in Figure 14, the spherical shape of the nanoparticles contributed to a lower contact hindrance with the polymer segments, and simultaneously, the SWCNTs with a larger interfacial contact area with the matrix showed a good advantage in hindering the diffusion of the PPS chains, resulting in higher $T_{\mathrm{g}}$. The performed tests confirmed that hybrids incorporating the optimized amounts of both nanofillers have enhanced dynamic mechanical performance when compared with composites reinforced only with SWCNTs wrapped in PEI. This phenomenon can be explained as follows: a SWCNT with a larger interfacial contact area is favorable to having a larger contact area with the matrix, which can positively contribute to the friction between the carbon nanotube and the matrix from the viewpoint of tribology. This larger contact area will restrict the mobility of PPS macromolecule chains and hinder the mobility of the PPS chains. Moreover, Han et al. ${ }^{[160]}$ used the melt mixing method to fabricate PPS/multiwalled carbon nanotube composites, and they reported that the homogenous dispersion of multiwalled carbon 

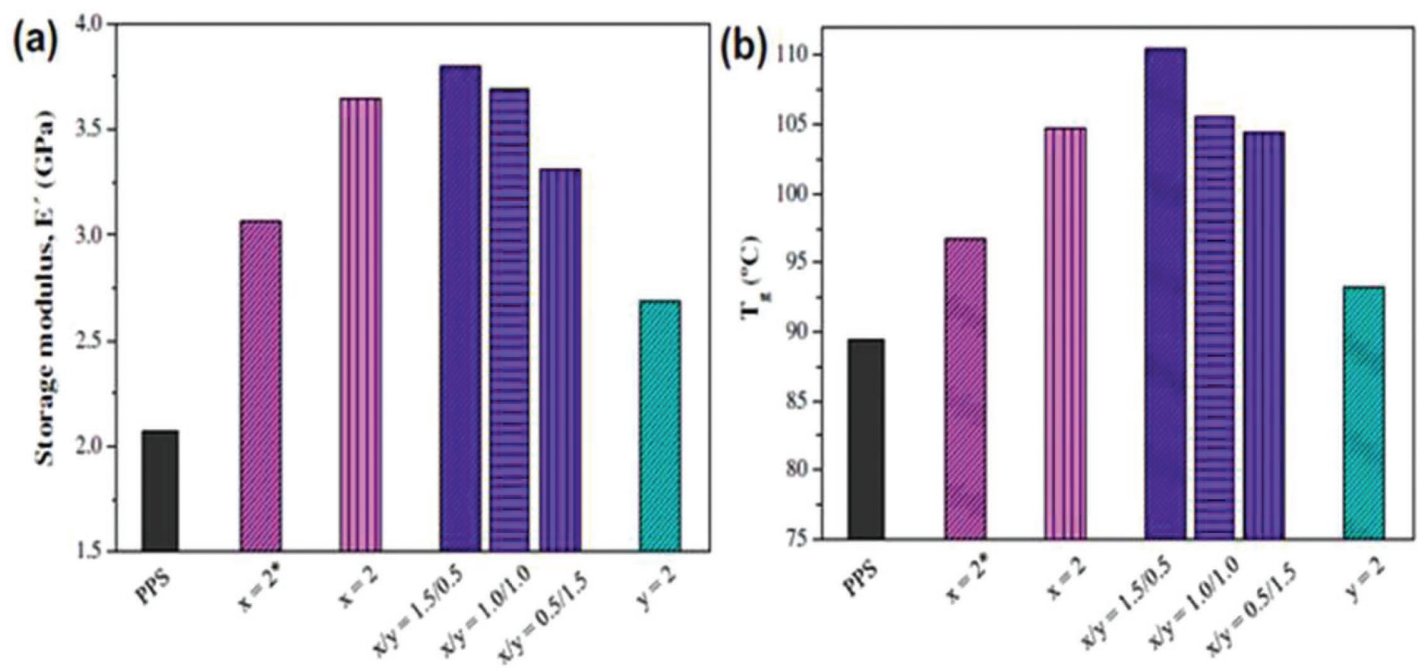

Figure 14. Comparison of the room temperature storage modulus $E^{\prime}$ a) and glass transition temperature $T_{\mathrm{g}}$ b) for the different PPS-based composites. To simplify the nomenclature, $x$ and $y$ denote the weight percentage of SWCNTS and IF-WS , respectively, and the composite incorporating nonwrapped SWCNTs is designated by $(*)$. Adapted with permission. ${ }^{[158]}$ Copyright 2012, Elsevier Science Ltd.

nanotubes in the polymer matrix contributed to the increasing complex viscosity of the PPS/MWCNT. Similarly, Yang et al. ${ }^{[156]}$ prepared PPS/MWCNT composites and observed an increased $T_{\mathrm{g}}$ and storage modulus of PPS via DMA.

\subsection{Other Additives in Blending}

In addition to the fillers or particles (e.g., short/long fibers, particles, and nanotubes), there are also some additives (e.g., antioxidants, ${ }^{[161]}$ heat stabilizers, ${ }^{[162]}$ UV stabilizers, ${ }^{[163]}$ carbon black, ${ }^{[164]}$ titanium dioxide, ${ }^{[165]}$ clay, ${ }^{[166]}$ mica, ${ }^{[145]}$ metal deactivators, ${ }^{[167,168]}$ plasticizers, ${ }^{[169]}$ pigments, ${ }^{[2]}$ adhesives, ${ }^{[170]}$ nucleating agents, ${ }^{[145]}$ and flame retardant ${ }^{[171]}$ compositions), which may be added in the industrial PPS materials to deionize and/ or acidify the PPS, or to reach some particular purposes or to achieve better functions.

Some examples are as follows:

- Zou et al. ${ }^{[166]}$ added a small amount of clay into PPS/polyamide 66 blends, and they found the morphology changed gradually from a sea-island structure into continuity and a lamellar supramolecular structure with the increase in clay content.

- The patent of US4418029A ${ }^{[162]}$ provides some information about the stabilized PPS fiber. In this patent, the heat stability of PPS was improved by the addition of cure retarders consisting of Group VIIA or Group VIIB metal salts of fatty acids to reduce gel formation during melt extrusion. Another patent (see US4535117A) ${ }^{[172]}$ introduced the addition of cure retarders containing metal sorbates, an alkaline earth metal nitrite for the improvement of the heat stability of PPS.

- Moreover, Bo et al. ${ }^{[173]}$ obtained a polymer blend consisting of linear PPS and hyperbranched PPS in the melt. They found the crystallization degree of the blends decreased with the increase in HPPS content. Both the storage modulus and loss modulus increased with the increase of HPPS content.
- Moreover, one can note in Figure 15 that the maximal tensile strength is obtained at the optimal content of $1 \%$ nano$\mathrm{SiO}_{2}$ and the elongation has the minimal value at the same content of $1 \%$ nano- $\mathrm{SiO}_{2}$. Young's modulus increases with an enhanced content in nano- $\mathrm{SiO}_{2}$. The main reason can be attributed to mobility restriction due to the nano- $\mathrm{SiO}_{2}$ added in the matrix.

\section{PPS—High-Performance Polymer/Properties of PPS}

\subsection{Thermal Behavior}

PPS exhibits good dimensional stability and thermal stability. This is mainly due to its ordered alternating arrangement of phenylene and sulfide atoms. Several studies have discussed these aspects: 1) thermal expansion/shrinkage/conductivity; 2) thermal stability; 3) thermal aging and thermal stability ${ }^{[174,175]}$; and 4) viscoelastic properties.

\subsubsection{Thermal Expansion/Shrinkage/Conductivity}

The temperature-dependent coefficient of thermal expansion for PPS was reported in previous research by Bonnet et al. ${ }^{[176]}$ as shown in a schematic figure of annealed PPS (see Figure 16). One can observe a shrinking above the glass-transition temperature $\left(105^{\circ} \mathrm{C}\right)$ while a softening appears in the zone of $10-30 \mathrm{~K}$, above $T_{\mathrm{a}}\left(T_{\mathrm{a}}\right.$ refers to the isothermal annealing temperature in this research).

In addition, Goyal et al. ${ }^{[177]}$ explored the thermal properties of new high-performance PPS/aluminum nitride (AIN) composites prepared with hot pressing technology for usage in electronic packaging. As seen in Figure 17, the linear thermal strain $(\Delta L / L)$ for pure PPS and the 29.3 vol\% composite are exhibited. The expansion occurred because there was a movement 

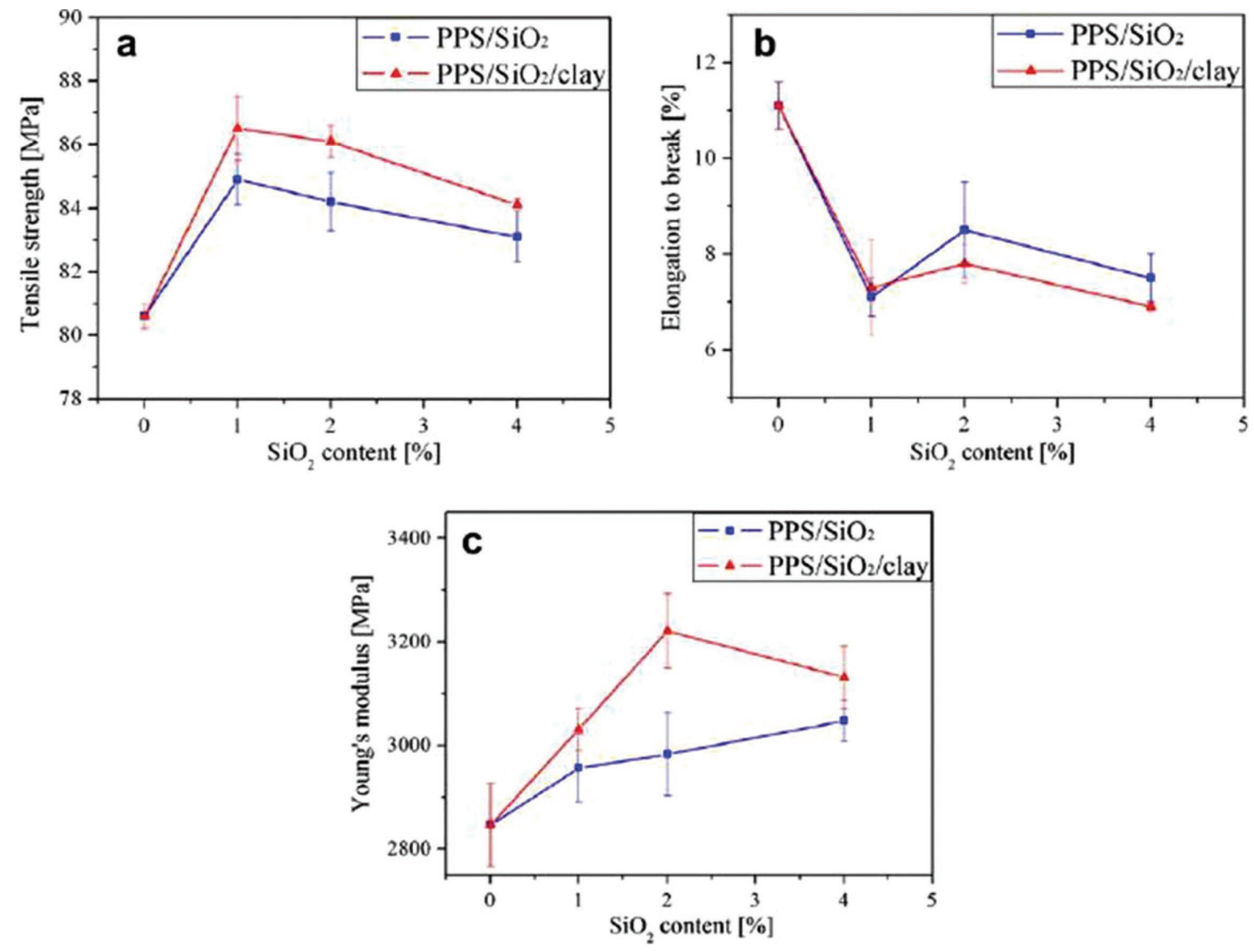

Figure 15. Tensile properties of PPS composites as a function of nano- $\mathrm{SiO}_{2}$ weight fraction: a) tensile strength, b) elongation to break, and c) Young's modulus. Adapted with permission. ${ }^{[13]}$ Copyright 2013, Elsevier Science Ltd.

of molecules or segments when they acquired energy with an increase in temperature. The thermal strain of the 29.1 vol\% was lower than that of pure PPS.

The thermal conductivity of PPS is $0.3 \mathrm{~W} \mathrm{~m}^{-1} \mathrm{~K}^{-1}$ at $25^{\circ} \mathrm{C}$. In the research of Pak et al. ${ }^{[178]}$ they concluded that PPS is

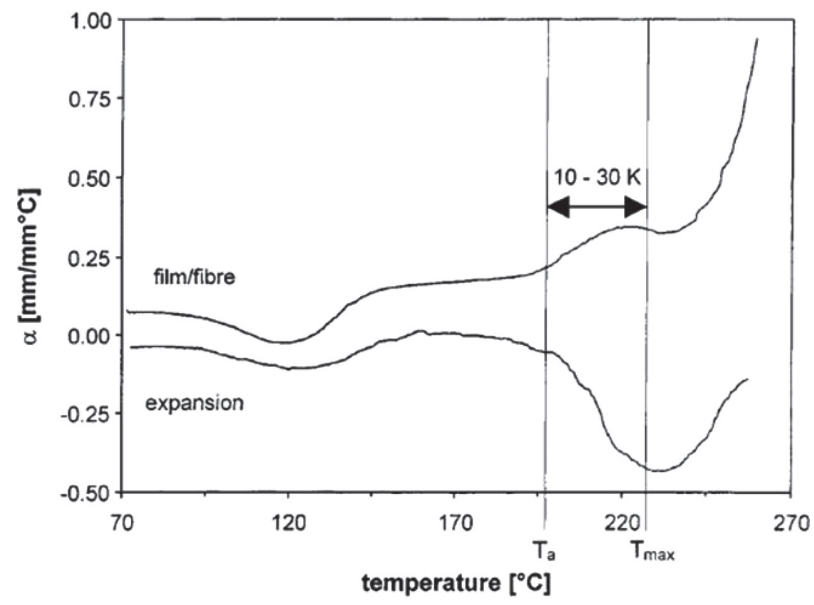

Figure 16. Temperature-dependent coefficient of thermal expansion for annealed PPS (expansion and film/fiber modus). Adapted with permission. ${ }^{[176]}$ Copyright 1999, Springer. suitable for the application as a thermally conductive polymer. These authors investigated the thermal conductivity of composites with a PPS matrix and MWCNT as fillers. The results showed that the thermal conductivity of the composite was affected by the interaction and interfacial thermal resistance

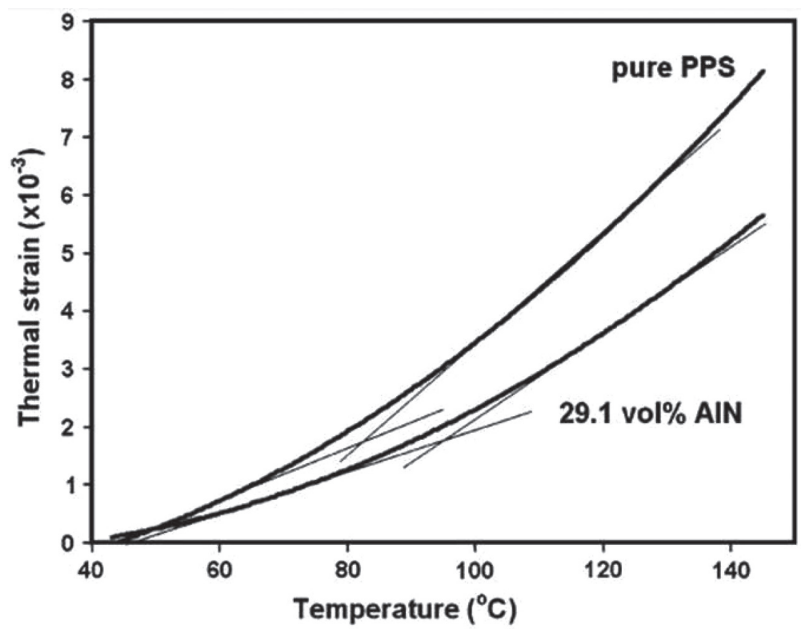

Figure 17. Thermal strain $(\Delta L / L)$ of composites as a function of temperature. Adapted with permission. ${ }^{[177]}$ Copyright 2011, Springer. 
between the PPS matrix and the MWCNTs. Similarly, the thermal conductivity of SWCNT buckypaper (BP) embedded in PPS was studied by Pascual et al. ${ }^{[179]}$ Furthermore, they also concluded that the thermal conductivity of PPS composites with SWCNTs could be well predicted by theoretical models. More interesting results can also be found in the reference of Khan et al. ${ }^{[180]}$ in which the study demonstrated that various carbon-based fillers, including pitch-based carbon fibers (CFs), multiwalled carbon nanotubes (MWCNTs), and graphene nanoplatelets (GNPs), can be dispersed in the polyphenylene sulfide (PPS) matrix to tailor the material's effective thermal conductivity. $\mathrm{Gu}$ et al. ${ }^{[181]}$ also conducted some innovative work concerning thermal conductivity of PPS-based materials. They found the thermal conductivities of the GNPs/PPS composites were improved with the increasing mass fraction of GNPs, and the thermally conductive coefficient of the fGNPs/ PPS composite 30 with $40 \mathrm{wt} \%$ fGNPs is greatly improved to $4.414 \mathrm{~W} \mathrm{~m}^{-1} \mathrm{~K}^{-1}$, approximately 19 times higher than that of the original PPS $\left(0.226 \mathrm{~W} \mathrm{~m}^{-1} \mathrm{~K}^{-1}\right)$. Moreover, in their other related studies, ${ }^{[182]}$ they employed hybrid fillers of micrometer boron nitride/nanometer boron nitride $(\mathrm{mBN} / \mathrm{nBN})$ to fabricate the highly thermally conductive insulating $\mathrm{mBN} /$ nBN/polyphenylene sulfide ([mBN/nBN]/PPS) composites via mechanical ball milling followed by the hot-compression method. The thermally conductive coefficient $(k)$, dielectric constant (e) and dielectric loss tangent values and thermal stabilities were all enhanced with the increasing addition of $\mathrm{mBN} / \mathrm{nBN}$ hybrid fillers.

\subsubsection{Thermal Stability}

Similarly, the kinetics of the thermal degradation of hyperbranched poly(phenylene sulfide) were studied,[183] and the results showed that the degradation temperature $\left(T_{d}\right)$ increased to a higher temperature with the increase in the heating rate. The change occurred from $476{ }^{\circ} \mathrm{C}$ for $5{ }^{\circ} \mathrm{C} \mathrm{min}-1$ to $529^{\circ} \mathrm{C}$ for $40{ }^{\circ} \mathrm{C} \mathrm{min}{ }^{-1}$. The change was from $28.2 \%$ for $5{ }^{\circ} \mathrm{C} \min ^{-1}$ to $45.4 \%$ for $40{ }^{\circ} \mathrm{C} \mathrm{min}-1$, and the char yield at $850{ }^{\circ} \mathrm{C}$ increased significantly with the rise in the rate.

Additionally, there are some other studies reporting the thermal stability of PPS or their reinforced parts. For example, high-resolution thermal gravimetric properties of polyphenylene sulfide film under four atmospheres were investigated by Li et al. ${ }^{[184]}$ and they found that there was a strong dependent relationship between thermal degradation parameters (e.g., temperature, the maximal degradation rate), testing atmosphere, and method. More intensively, the kinetics behavior on pyrolysis of PPS under different oxygen concentrations was examined by Teng et al. ${ }^{[185]}$ and they concluded that only one stage occurred in inert atmosphere while two stages existed in oxidative atmosphere in the pyrolysis process of polyphenylene sulfide. The activation energy ${ }^{[186]}$ of PPS blending can also be affected by the blending composition. In addition, an increased heating rate ${ }^{[187]}$ and partial crosslinking ${ }^{[188]}$ can enhance the initial thermal decomposition temperature of PPS blending materials. Moreover, Tanthapanichakoon et al. ${ }^{[189]}$ examined the degradation behavior of semicrystalline PPS bag-filter materials by $\mathrm{NO}$ and $\mathrm{O}_{2}$ at high temperature, and they summarized that the fabric strength depended on the crystallinity and the damages/ defects in the amorphous region.

\subsubsection{Thermal Aging and Thermal Degradation}

In this section, the aspects of thermal aging and degradation phenomena of PPS after aging are emphasized, and we try to investigate the degradation process of PPS according to classical studies. ${ }^{[190]}$ As mentioned above, PPS has good stability against water and acid as well as many other chemicals due to the sulfur atoms which can endow the polymer with flexibility. These sulfur atoms, however, cause problems such as so-called crosslinking and coloration when the polymer is heated in the presence of oxygen. This significantly limits the utilization of the polymer. According to the previous studies, the change in PPS during thermal curing may result in the main chain scission or crosslinking reactions. ${ }^{[191]}$ Ref. [192] reported the isothermal kinetic behavior under the fluidized-bed condition of linear PPS and the branched PPS, which was formed by curing at $340{ }^{\circ} \mathrm{C}$. The authors concluded that the bond strength influenced the activation energies required for cleavage and the formation of the two families of products (see Figure 18). When the pyrolysis temperature increased, more $\mathrm{Ph}-\mathrm{S}$ bonds were cleaved; therefore, the pyro-products obtained were of low molecular weight (dimer and trimer), and the secondary reactions yielding dibenzothiophenes became dominant. Moreover, this pyrolysis method can provide a better understanding regarding the aspect of polymer structure via the examination of their thermal fragmentation products.

The exact aging process of PPS was clarified in depth by Ehlers et al. ${ }^{[7]}$ They concluded that cleavage of carbon-sulfur bonds and abstraction of hydrogen from some of the rings resulted in chain fragments with phenyl and phenylmercapto end groups. Cleavage of the $\mathrm{C}-\mathrm{SH}$ bonds and abstraction of more hydrogen led to hydrogen sulfide. As shown in Table 5, hydrogen sulfide was the predominant volatile product at the lower temperature, and hydrogen at the two higher temperatures. Only very small amounts of other volatiles were present. Above $450{ }^{\circ} \mathrm{C}$, the reactions tended to be more complex with the formation of some water, carbon dioxide and carbon monoxide as well as sulfur dioxide.

Thermal degradation of polyphenylene sulfide (PPS) film in four types of atmospheres including air, nitrogen, and helium as well as argon was studied by Li et al. ${ }^{[184]}$ In this research, they pointed out that most polymers contain weak bonds that break with a higher probability than other stronger bonds. When the thermal energy began to surpass the bond energies of various bonds in the PPS chains, a random chain scission occurred and the rate of degradation enhanced rapidly. Similarly, thermal degradation of Poly (phenylene sulfide) was examined by Christopher et al. ${ }^{[6]}$ through a weight loss method. They indicated that in a closed system, poly(phenylene sulfide) broke down by chain-scission and transferred reactions, yielding largely an involatile residue containing some low molecular weight chain fragments. Moreover, an understanding that the mechanism of PPS involved a combination of crosslinking, chain scission, and aging reactions was concluded in the literature of ref. [193]. 


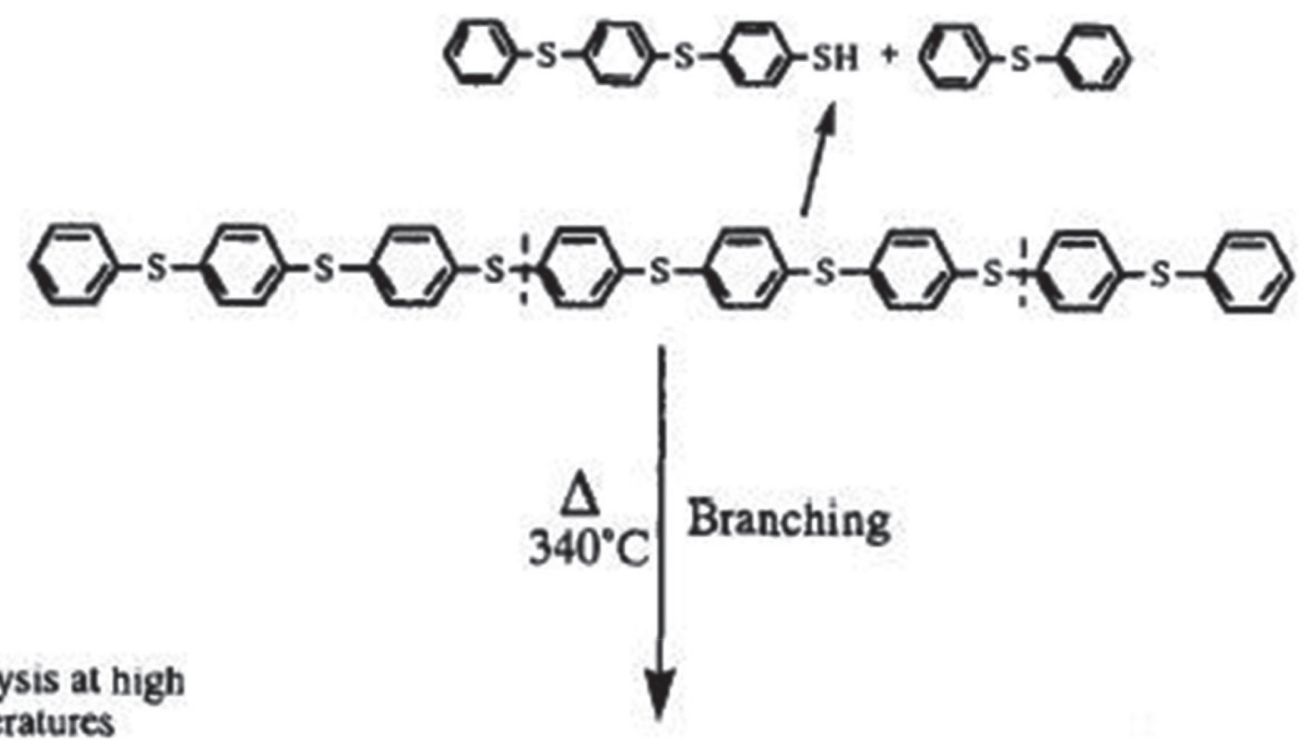

Pyrolysis at high
temperatures

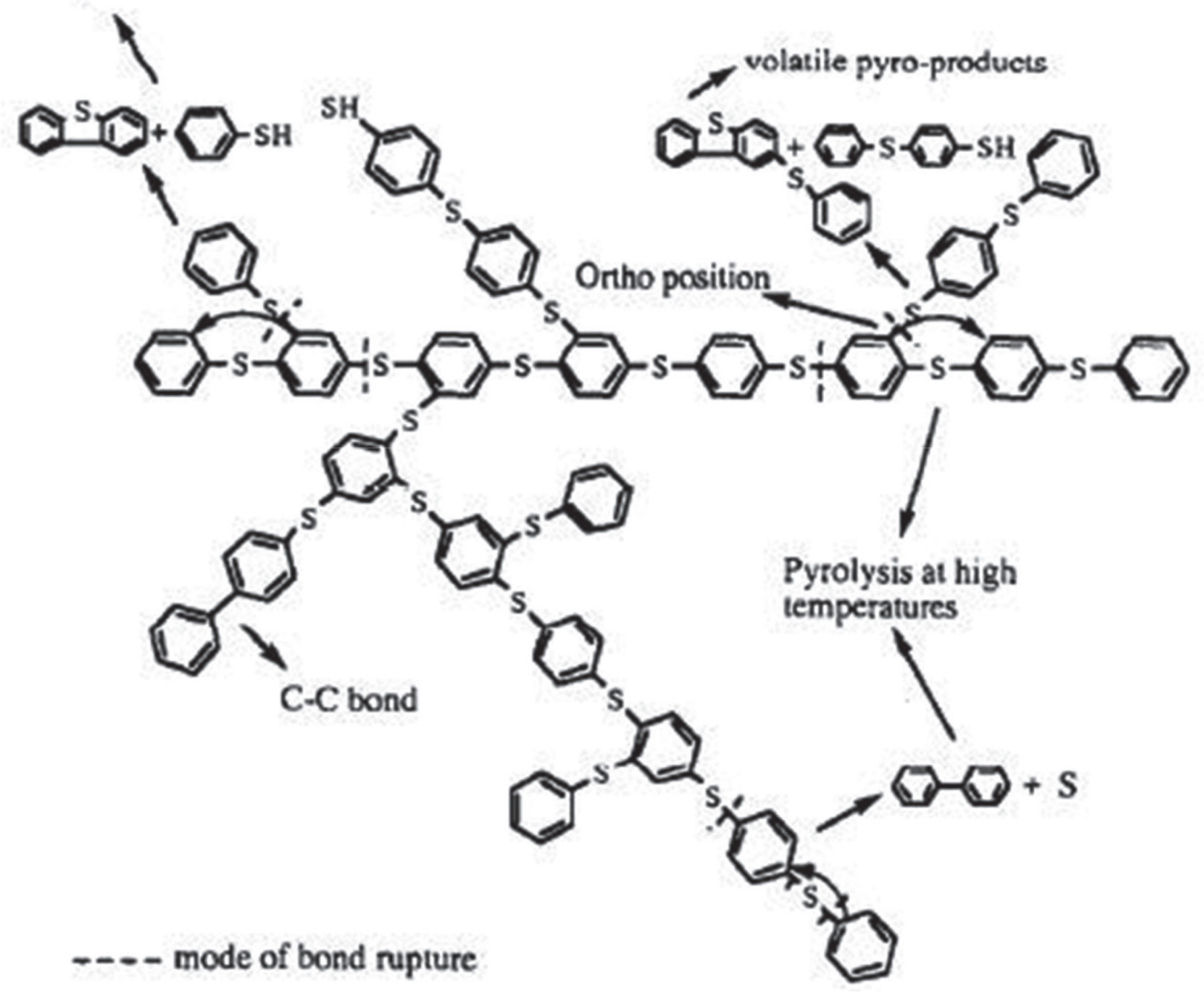

Figure 18. Scheme of curing of LPPS under nitrogen at $340^{\circ} \mathrm{C}$. Adapted with permission. ${ }^{[192]}$ Copyright 1993, Elsevier Science Ltd.

Similarly, Deslauriers et al. ${ }^{[194]}$ studied the aspects of PPS degradation and stabilization. They found that polymer end groups played an important role in the thermaloxidative coloration of PPS. In semicrystalline samples PPS, the end groups or any other imperfection would be concentrated at spherulite boundaries in the amorphous phase. Moreover, an obvious degradation of the mechanical properties can be observed due to the serious degradation that was enhanced with the increase in treatment temperature and time. ${ }^{[195]}$ 
Table 5. Analysis of the residues of poly (1,4-phenylene sulfide). Adapted with permission. ${ }^{[7]}$ Copyright 1969, Wiley Periodicals Inc.

\begin{tabular}{lrccccccc}
\hline \multicolumn{10}{l}{ Analysis of volatiles from PPS } \\
\hline Temperature & \multicolumn{10}{c}{ Volatile products, [mole \%] } \\
\cline { 2 - 9 }$\left[{ }^{\circ} \mathrm{C}\right]$ & $\mathrm{H}_{2}$ & $\mathrm{H}_{2} \mathrm{O}$ & $\mathrm{CH}_{4}$ & $\mathrm{CO}$ & $\mathrm{H}_{2} \mathrm{~S}$ & $\mathrm{CO}_{2}$ & $\mathrm{SO}_{2}$ & $\mathrm{C}_{6} \mathrm{H}_{6}$ \\
\hline $20-450$ & 8.5 & 0.4 & 1.4 & 1.0 & 84.5 & 1.1 & 1.8 & 1.3 \\
$450-550$ & 59.7 & 3.1 & 1.2 & 2.9 & 29.8 & 0.2 & - & 3.1 \\
$550-620$ & 61.4 & 2.8 & 1.4 & 2.3 & 28.7 & 0.2 & - & 3.2 \\
\hline
\end{tabular}

\subsubsection{Viscoelastic Properties}

Generally, the classical theory of elasticity is concerned with the mechanical properties of elastic solids in accordance with Hooke's law. In this case, stress is always directly proportional to strain in a small deformation; however, the mechanical properties of elastic solids are definitely independent of the rate of strain. The classical theory of hydrodynamics addresses the properties of viscous liquids, and in this case, the viscous liquids follow Newton's law, where the stress is always directly proportional to rate of strain but independent of the strain itself. However, the materials with viscoelasticity exhibit both viscous and elastic characteristics when undergoing deformation. That is, viscoelastic materials have both elements of elastic and viscous materials. The viscoelastic response of PPS or PPS-based materials has been studied over the past several decades. ${ }^{[136,196-202]}$ In this section, the principle purpose is focused on overviewing viscoelastic properties of PPS polymer materials.

Dynamic mechanical analysis (DMA or DMTA) helps us to obtain the related values and parameters including the storage modulus and loss modulus as well as the parameters concerning the damping behavior of polymers. With the DMA method, Guo et al. ${ }^{[200]}$ investigated the isothermal physical aging behavior of PPS film by creep and stress relaxation, and they indicated stress and strain remained in the linear viscoelastic regime. Annealing effects in PPS were also studied by DMA in the reference of. ${ }^{[203]}$ Annealing of injection molded Izod bars was performed in a vacuum oven at temperatures of $160,180,200$, and $220^{\circ} \mathrm{C}$ with a constant annealing time at $4 \mathrm{~h}$. The authors found an area of the increased endotherm with the increase in the annealing temperature. Similarly, thermal behaviors and viscoelastic properties of PPS/epoxy resin were studied, ${ }^{[204]}$ and the results showed that the epoxy resin can promote degradation and branching of PPS during melting mixing due to its poor thermal stability.

Moreover, the morphology and mechanical performance of carbon fiber reinforced PPS composites was reported, ${ }^{[205]}$ and the results showed the variation of the apparent storage modulus $\left(E^{\prime}\right)$ and the loss factor $(\tan \delta)$ as a function of temperature for different molding and loading conditions. Furthermore, the authors showed that the treatment temperature could have a remarkable effect on the viscoelastic properties although the crystallinity of the composite did not change with molding conditions.

The effects of annealing on the relaxation behavior and charge trapping in film-processed PPS was studied in ref. [84]
In this study, DMA results showed a corresponding increase in the temperature location of the dissipation peak and a decrease in its amplitude when $T_{\alpha}$ increased above $100{ }^{\circ} \mathrm{C}$.

Some researchers also focus on the rheological properties of PPS or PPS-related materials..$^{[206-208]}$ In detail, PPS and PPS/MWCNTs (multiwall nanotubes) were prepared by Yang et al. ${ }^{[156]}$ and as shown in Figure 19, they evaluated the change of viscosity before and after adding multiwall nanotubes and explained an obvious improvement on viscoelasticity of the nanocomposites due to the presence of the nanotube network interpenetrating into the PPS matrix.

In ref. [209] the research studied the rheological behavior of polyphenylene sulfide (Ryton-type PPS and Fortron PPS). The results showed that the apparent viscosity of the Ryton PPS decreased obviously with the increase in the shearing rate or shearing stress.

\subsection{Mechanical Properties and Applications}

\subsubsection{Factors Affecting the Mechanical Behaviors of Fiber Reinforced Composites}

Fiber Selection: Normally, fiber can be divided into three categories according to its origin: plant, animal, or mineral. There are major structural components in all plant fibers while protein exists in animal fibers. In addition, high-performance plant fibers possess much higher strengths and stiffness than available animal fibers. Comparatively, mineral-based natural fibers are less frequently used due to health issues associated with carcinogenic substances acquired through ingestion. As a result, plant fibers are the most suitable and popular for utilization in composites that have high structural strength requirements.

Matrix Selection: In a fiber-reinforced composite, the matrix plays an important role to prevent consequences from harsh environments including thermal impact as well as chemical resistance. Moreover, it can transfer the load to the fibers. In commercial utilizations, polymeric materials are the most commonly applied matrix due to their light weight and good process ability at a relatively low temperature.

Fiber-Matrix Adhesion: Fiber-reinforced polymer composites can transfer the applied force to the surrounding fibers. As a result, the bonding strength between the fiber and matrix plays an important role for the mechanical properties of composites. Some planted fibers may have some drawbacks due to the poor bonding from the hydrophilic nature of the fiber and the hydrophobic nature of the resin. Some solutions to overcome these drawbacks were proposed by using mechanical interlocking, chemical bonding, electrostatic bonding, and interdiffusion bonding as well as a coupling agent or chemical pretreatment. $^{[210,211]}$

Fiber Dispersion: Fiber dispersion varies according to the fiber length (short or long) and processing factors such as pressure and temperature. Good dispersion of fibers favors a good bonding, which can improve the mechanical properties. ${ }^{[212]}$

Fiber Orientation: Generally, the composites with the fibers aligned parallel to the direction of the applied load can have the best mechanical properties. By increasing the fiber orientation 

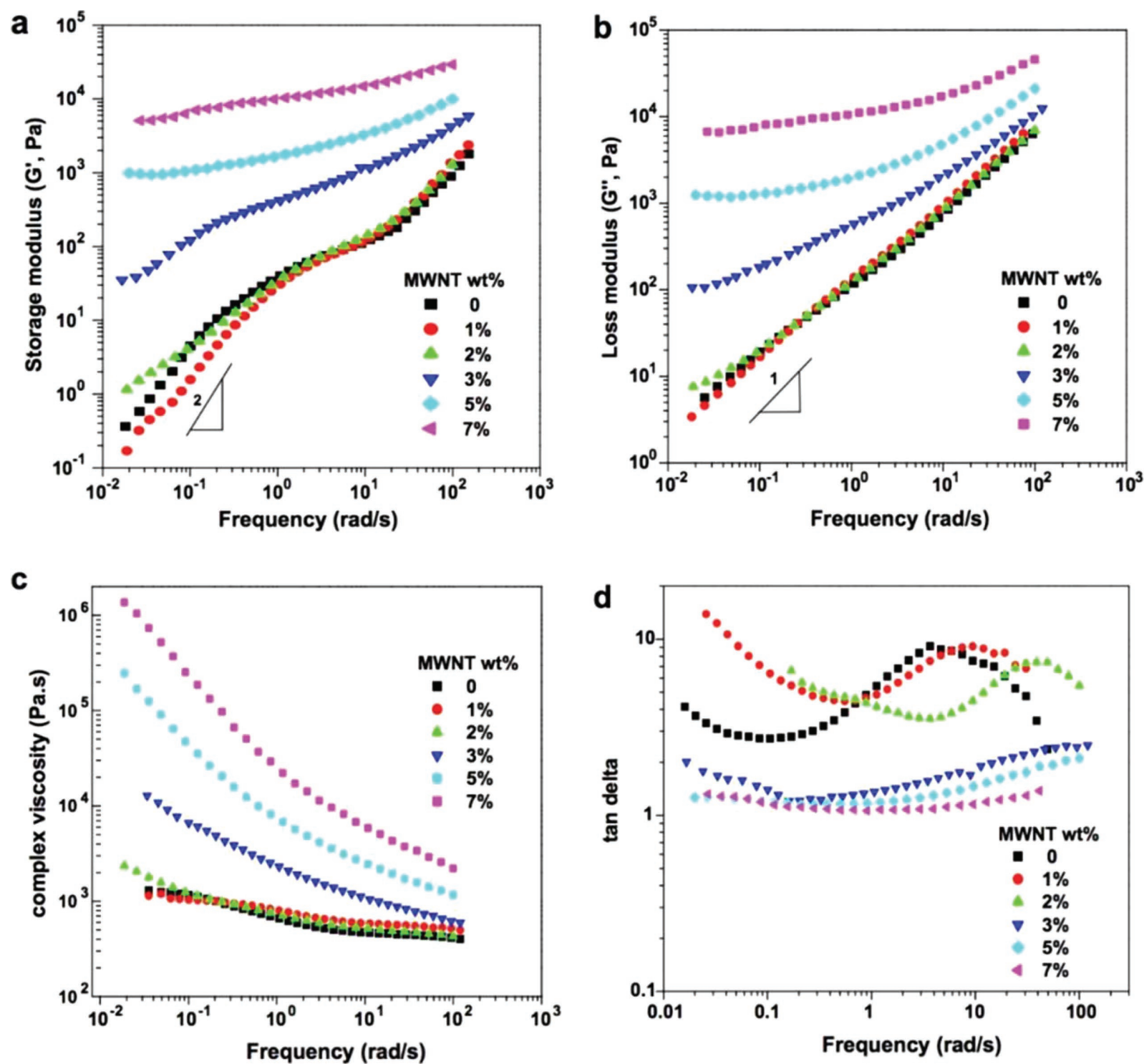

Figure 19. a) Storage modulus; b) loss modulus; c) complex viscosity; d) tan delta versus frequency for PPS and PPS/MWCNTs composites with various MWCNTs loading. Rheology testing performed at $320^{\circ} \mathrm{C}$. Adapted with permission. ${ }^{[156]}$ Copyright 2009, Elsevier Science Ltd.

with respect to the fiber loading, one can reduce the strength and modulus. In addition, different strengths and moduli correspond to various physical phenomena including different self-heating properties and damage propagation.

Used Technique in Composite Manufacturing: Compression molding, injection molding, and resin transfer molding ${ }^{[213,214]}$ are the three commonly used techniques to fabricate the reinforced polymer composites. It is necessary to point out that the final properties vary along with the evolution of the fabrication process by using different parameters, including processing, pressure, and temperature as well as speed.

Porosity of Composites: Porosity can occur due to the inclusion of air bubbles while pouring resin over the fibers at the time of processing. The formation and the influence mechanism of composite porosity were studied by Li et al.[215] They showed that the main reason that porosity was formed was the poor wettability of fibers, the retention of vapor molecules and the molecular volatilization generated during the crosslinking reaction. Additionally, the increased cure pressure can decrease the porosity factor and porosity size remarkably.

Void Content in Composites: There is a possibility that air or other volatiles will be trapped in the composites during the fabrication of composites. These air or other volatiles can form microvoids in the composites, which can affect the mechanical properties of composites. For example, the influence of voids on the flexural fatigue performance of unidirectional carbon fiber composites was investigated by Chambers et al. ${ }^{[216]}$ They concluded that a strong correlation existed between large voids (area $>0.03 \mathrm{~mm}^{2}$ ), and these voids had a detrimental effect on the mechanical properties. Furthermore, they reported that this detrimental effect can be attributed to the voids on the crack propagation in the resin-rich interply regions. 

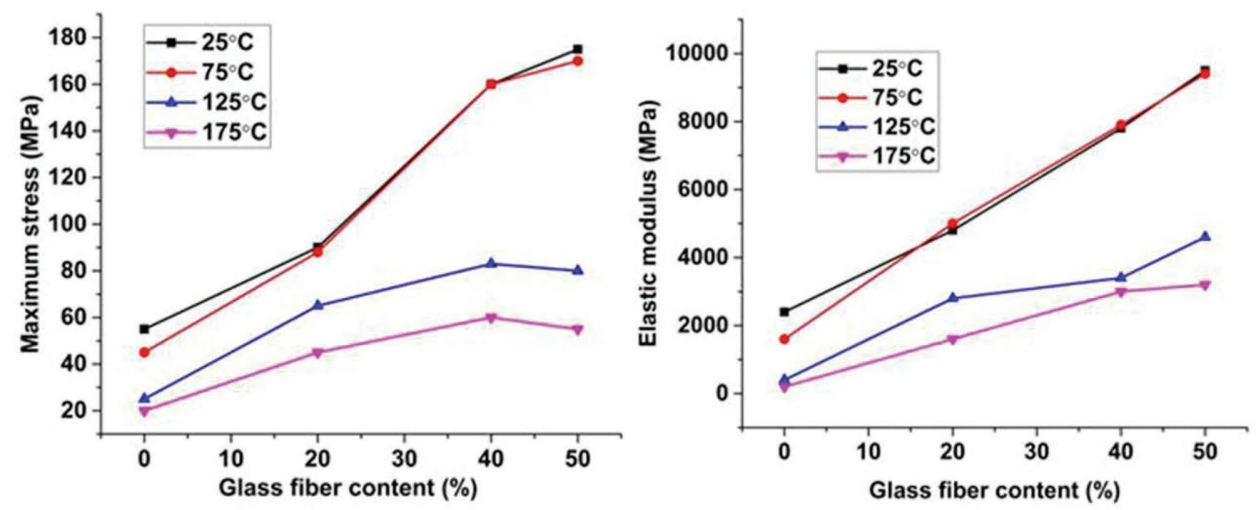

Figure 20. Maximum stress (left) versus elastic modulus (right) as a function of glass fiber content for PPS/glass fiber composites at various testing temperatures. Adapted with permission. ${ }^{[225]}$ Copyright 1996, Springer.

\subsubsection{General Mechanical Behaviors of PPS and PPS Composites}

In this section, we particularly focus on the mechanical properties of PPS and PPS composites. ${ }^{[19,135,217-220]}$ There is a wide range of studies concerning PPS-based composites from the aspect of mechanical properties, including 1) tensile behavior and impact test behavior; 2) bending or flexion behavior; 3) shear behavior; 4) compressive behavior; and 5) fatigue behavior.

Tensile Behavior and Impact Test Behavior: Tensile behaviors are generally affected by environmental conditions. ${ }^{[221,222]}$ In the previous studies, environmental effects on glass reinforced PPS composites were studied by Lou et al. ${ }^{[223]}$ They revealed that this material possessed excellent mechanical properties at temperatures above the glass transition temperature, and this was due to high crystallinity and long glass reinforcement. They also clarified that the loss in properties was caused principally by the degradation of the fiber-matrix interface. Good strength property retentions were observed after exposure to both hot air and water.

Zhai et al. ${ }^{[24]}$ also showed that the mechanical properties of glass fiber reinforced PPS composites were affected by thermal treatment. Moreover, the effect of temperature on the mechanical properties was studied, ${ }^{[225]}$ and the result showed maximum stress and elastic modulus increased obviously with the increase in glass fiber content below the glass transition temperature of the PPS matrix. In particular, the results showed the maximum stress and elastic modulus of PPS composites at various temperatures (see Figure 20).

Moreover, PPS, as a high-performance polymer, is always used as a matrix of composites, and there is a wide range of reports to clarify this aspect. C/PPS laminates subjected to monotonic off-axis tensile loadings showed strongly matrixdominated response results in an elastic-ductile behavior, while the PPS resin at $120{ }^{\circ} \mathrm{C}$ displayed a lower longitudinal stress with a long longitudinal strain.

Similarly, PPS, as a good blending composition, shows good mechanical properties when blended with other polymers. For example, in the research of ref. [138] the authors reported the mechanical properties of PPS with other LCPs, and the detailed results are shown in Table 6:
The effect of thermal treatment on the tensile properties of PPS composites reinforced by carbon fibers was studied by Pantelakis et al. ${ }^{[195]}$ and they exhibited an appreciable decrease in tensile strength when these specimens were subjected to thermal treatment. The report of ref. [226] also studied the mechanical behaviors of PPS fiber materials after heat treatment, and they found that excess heat treatment, longer than 2 days, resulted in over-oxidative crosslinking and was detrimental to the thermal mechanical properties of the samples at high temperature. In addition, Garrell et al. ${ }^{[35]}$ studied the mechanical properties of PPS bonded with Nd-Fe-B permanent magnets from $-40{ }^{\circ} \mathrm{C}$ to $180^{\circ} \mathrm{C}$, and they revealed the ultimate tensile strength of PPS bonded magnets decreased with the increase in temperature.

Moreover, the influence of temperature on the impact behavior of woven-ply carbon fiber reinforced PPS composites was studied by Wang et al.[227] Figure 21 is the experimental equipment used for the low velocity impact tests. As shown in the results in Figure 22, the temperature has a crucial effect on the limited propagation of delamination due to the geometry of the woven plate. The shape of the impact-induced damage of the specimens for 15 and $25 \mathrm{~J}$ impacts transformed from nearly circular to oval or even cross-shaped with increasing temperature. In addition, the results showed that the damage propagation along the longitudinal direction was seriously confined at elevated temperatures.

Table 6. Mechanical properties of the injection molded blends. Adapted with permission. ${ }^{[138]}$ Copyright 1992, Wiley Periodicals Inc.

\begin{tabular}{lcccc}
\hline Materials & $\begin{array}{c}\text { Tensile } \\
\text { strength } \\
{[\mathrm{MPa}]}\end{array}$ & $\begin{array}{c}\text { Elastic } \\
\text { modulus } \\
{[\mathrm{MPa}]}\end{array}$ & $\begin{array}{c}\text { Elongation } \\
{[\%]}\end{array}$ & $\begin{array}{c}\text { Charpy impact } \\
\text { strength } \\
{\left[\mathrm{k}_{\mathrm{m}}^{-2}\right]}\end{array}$ \\
\hline PPS/0 & 82 & 3697 & 2.7 & 8.0 \\
PPS/5 & 84 & 4035 & 2.9 & 12 \\
PPS/10 & 87 & 4040 & 3.4 & 24 \\
PPS/20 & 73 & 4512 & 2.2 & 15 \\
PPS/30 & 69 & 4952 & 1.7 & 14 \\
PPS/50 & 100 & 6447 & 2.1 & 13 \\
\hline
\end{tabular}




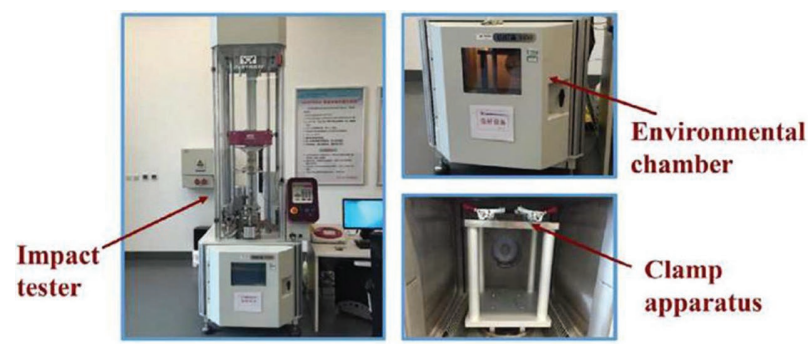

Figure 21. Experimental equipment used for low-velocity impact tests. Adapted with permission. ${ }^{[227]}$ Copyright 2018, Elsevier Science Ltd.

In addition, Sinmacelik et al. ${ }^{[228]}$ studied the nature weathering effects on the mechanical and surface properties of PPS composites. They showed that the percentage decrease in the impact strength after natural weathering of fiber/particle-filled PPS composite was smaller when compared to short fiber-filled PPS composite.

The impact damage effect on the fatigue life of PPS composites reinforced using carbon fiber was evaluated by Kytyr et al. ${ }^{[229]}$ and they revealed that the module of elasticity computed from three-point bending elasticity decreased without a significant influence of the impactor diameter. In addition, they concluded frequencies, ultrasound wave propagation, and bending stiffness were suitable as measurement parameters for the evaluation of the material degradation process in C/PPS composite during its fatigue life.

Bending or Flexion Behavior: The load bearing performance of pin-connected carbon/PPS composites under static loading conditions was investigated by Yylmaz et al. ${ }^{[230]}$ and they found the bearing strength of the pin connection highly depended on the joint and material parameters (for example the connection geometry, fiber orientation, layer orientation, and pressure distribution along the plate thickness). Furthermore, the effect of carbon fiber reinforcement on the mechanical properties of polyamide 6/PPS composites was studied in, ${ }^{[28]}$ and the report revealed that with the addition of carbon fibers, the strength, and modulus improved while the breaking elongation rate and impact strength just decreased to a small degree. In this

RT

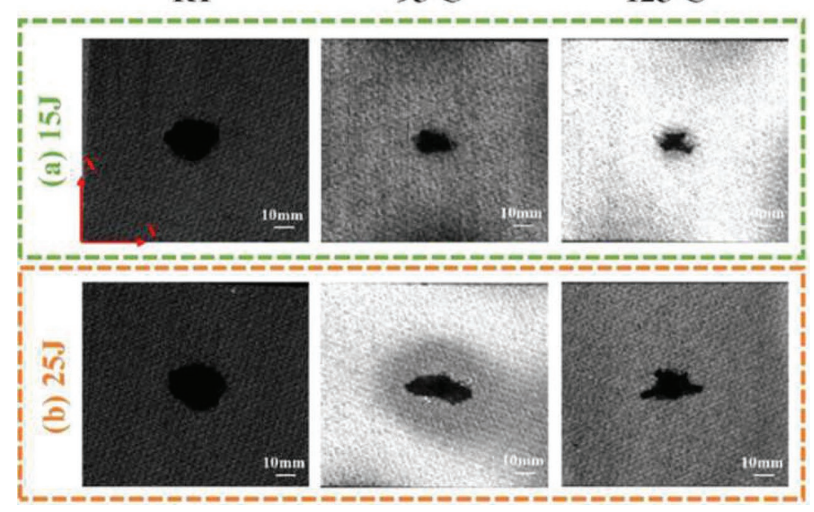

Figure 22. C-scan inspection of CF/PPS impacted specimens for 15 and $25 \mathrm{~J}$ at different temperatures: a) $15 \mathrm{~J}$; b) $25 \mathrm{~J}$. Adapted with permission. ${ }^{[227]}$ Copyright 2018, Elsevier Science Ltd. study, the authors revealed that bending strength and bending modulus increased apparently with the addition of carbon fiber. Luo et al. ${ }^{[130]}$ prepared PPS/ polytetrafluoroethylene composite reinforced with short carbon fibers, and they revealed that the incorporation of carbon fibers apparently improved the tensile strength, flexural modulus, and hardness of PPS/PTFE blends.

Shear Behavior: The ILSS, translaminar and interplane shear strength as well as transverse stretch strength are the most commonly used measures to evaluate the quality of bonding in the structural pieces. In other application of PPS, the joint part from polymer composites is very significant for the aerospace industry since aircraft structures are large and complex and cannot be manufactured in a single step. PPS-based composites are popularly applied as a joint part in this domain. For example, welded glass fiber reinforced PPS joints were used and tested in a wide range of temperatures by Koutras et al. ${ }^{[231]}$ This research reported that the lap shear strength decreased with increase in temperature. The shear strength behaviors of PPS/glass fiber composites was also studied by Costa et al. ${ }^{[232]}$ and they considered different environmental condition effects. One can see the fracture, observed by the ILSS, in Figure 23. The results showed that fractures (submitted to a) no conditioning, b) hydrothermal conditioning and c) seawater conditioning) followed the same multiple delaminating and interlaminar cracks at the horizontal and vertical positions; however, the fracture submitted to UV conditioning exhibited a compressive buckling or compressive yielding in some parts situated at the upper part of the beam.

Compressive Behavior: The compressive behavior of notched and unnotched carbon woven-ply PPS thermoplastic laminates at different temperatures was studied by Wang et al. ${ }^{[233]}$ The results (see Figure 24) showed that the stress-strain curve of the unnotched specimen at RT had a similar linear trend as that of the notched one. Nonlinearity also existed for the notched specimen at elevated temperatures, which was associated with the softened matrix. Comparatively, as seen in Figures 25 and 26, the matrix and interface cracks can be seen in notched specimens at $\mathrm{RT}$ and $95{ }^{\circ} \mathrm{C}$, which were similar to the unnotched specimens. They concluded that a transition of failure modes existed from the wedge shear failure and an obvious delamination at RT, whereas in the other case, kink bands or even microbuckling occurred at elevated temperatures.

Postfire compressive behaviors of carbon fibers wovenply PPS laminates were studied by Maaroufi et al. ${ }^{[234,235]}$ and Figure 27 shows the experimental setup and anti bulking fixture. In addition, the different compressive responses were compared for all fire-testing conditions in Figure 28. In their similar works, ${ }^{[234-236]}$ the authors concluded that a compressive loading led to further delamination, which was explained by the mechanism in Figure 29. In particular, localized bending at the crimp was found to cause microbuckling in woven-ply misaligned structures. Furthermore, microbuckling occurred along with a plastic deformation of the matrix in highly ductile matrix systems, resulting in the formation of the deformed inclined kink bands also called plastic buckling.

In addition, the effect of microsized and nanosized carbon fillers on the thermal properties of PPS composites was studied by Khan et al. ${ }^{[237]}$ and they found that various carbon-based fillers, including pitch-based carbon fibers, multiwalled carbon 

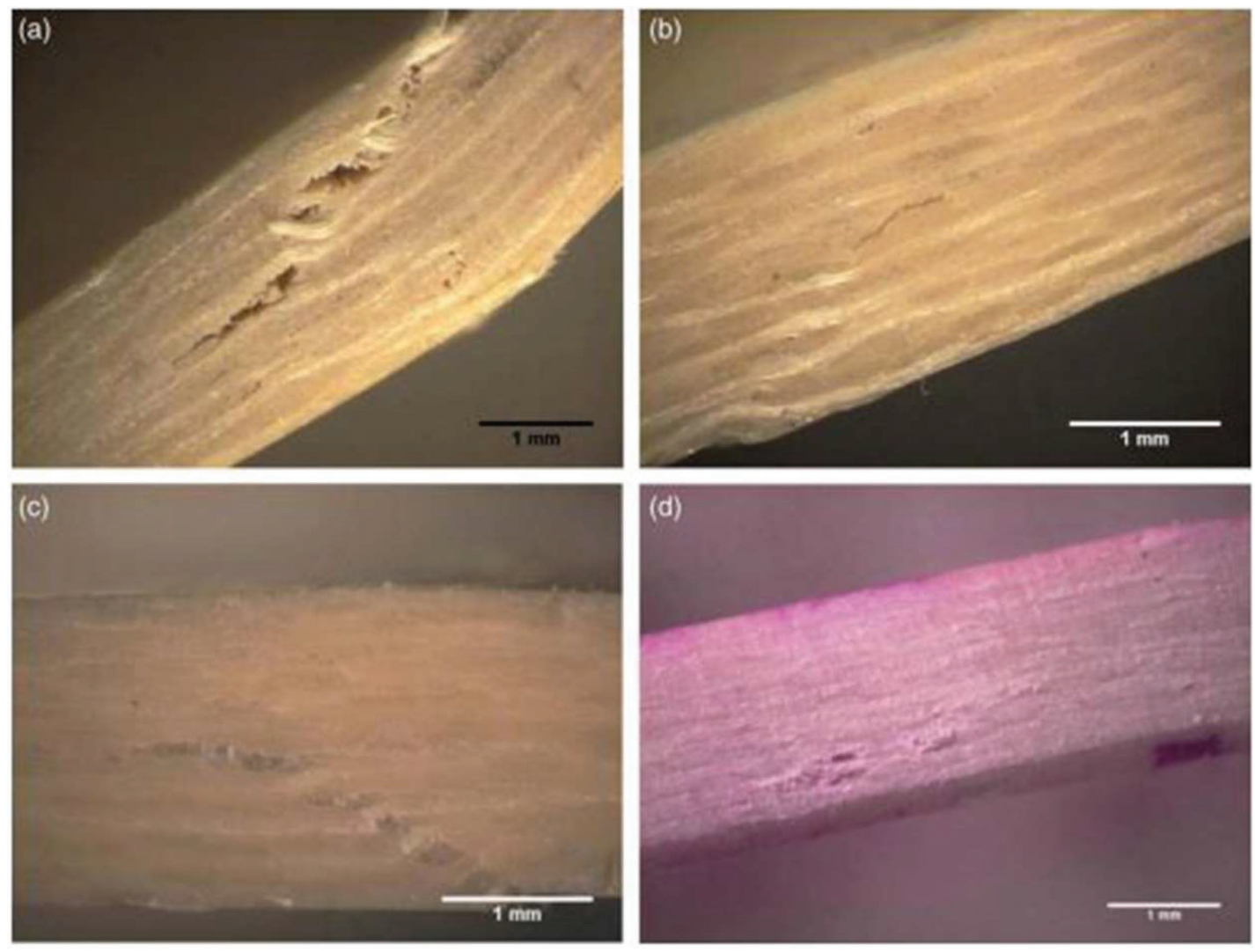

Figure 23. Representative fracture observed by the interlaminar shear strength test: a) no conditioning, b) hygrothermal conditioning, c) seawater conditioning and d) UV conditioning. Adapted with permission. ${ }^{[232]}$ Copyright 2018, Elsevier Science Ltd.

nanotubes, and GNPs, can be dispersed in the PPS matrix to tailor the material's compressive modulus.

Furthermore, the effect of a carbon-based filler on the glass transition temperature $\left(T_{\mathrm{g}}\right)$ of the PPS composites was discussed. The hindrance of mobility of the polymer chains caused by the presence of microsized and nanosized filler particles could increase the $T_{\mathrm{g}}$ of the composites.

Fatigue Behavior: In the aspect of fatigue behaviors, there is a wide range of earlier published studies. The fatigue behavior of the material blended by using polyphenylene ether ketone and PPS was studied by Zhou et al. ${ }^{[238]}$ They found the constructed S-N curves shifted their trends dramatically at the maximum cyclic stress. In addition, Baere et al. ${ }^{[239]}$ examined the interlaminar behavior of a 5-harness carbon fabric reinforced PPS by using lap experiments, they considered the quasi-static, hysteresis, and fatigue loading conditions and they found that under quasi-static loading, both until failure and with continuously loading and unloading with an increasing maximum load, there was no crack growth. For fatigue loading, cracks growth can be seen clearly from the beginning of fatigue life. In other works of ref. [240] they evaluated two types of welding procedures (extra sheets of PPS were added to the bond). It was found that one-sided welding yielded irreproducible results, not only between separate welding cycles with the same settings but also between the three specimens originating from one cycle. However, the two-sided welding showed reproducible results, both within one welding cycle and different welding cycles.

The ultrasonic fatigue behavior and microstructure of carbon fiber fabric reinforced PPS in the very high cycle fatigue regime were studied in the report, ${ }^{[241]}$ and the authors analyzed the very high cycle fatigue behavior of a carbon fiber twill 2/2 fabric reinforced PPS (CF-PPS) systematically up to $10^{9}$ loading cycles. The different stress ratios between $R=0.21$ and 0.51 showed an exponential decrease of the bearable stress amplitude in the range between $10^{6}$ and $10^{9}$ cycles. One can observe the following in Figure 30: the results showed an exponential decrease of the bearable shear stress amplitude over the number of cycles until delamination. Furthermore, it was marked as a prevention interval in which the specimen failure of all further experiments would appear with a probability of $95 \%$.

Moreover, the environmental effects on glass reinforced PPS composites were studied by Lou et al. ${ }^{[223]}$ They revealed that this material had excellent mechanical properties at temperatures much higher than the glass transition temperature, and good fatigue property retentions were observed after exposure to both hot air and water. Regarding the fatigue behavior of glass and carbon fiber reinforced engineering thermoplastics PPS, the $\mathrm{S}-\mathrm{N}$ curve appeared linear with no evidence of a fatigue limit up to $10^{6}$ cycles. The glass reinforced PPS composite degraded while the carbon reinforced materials with a 

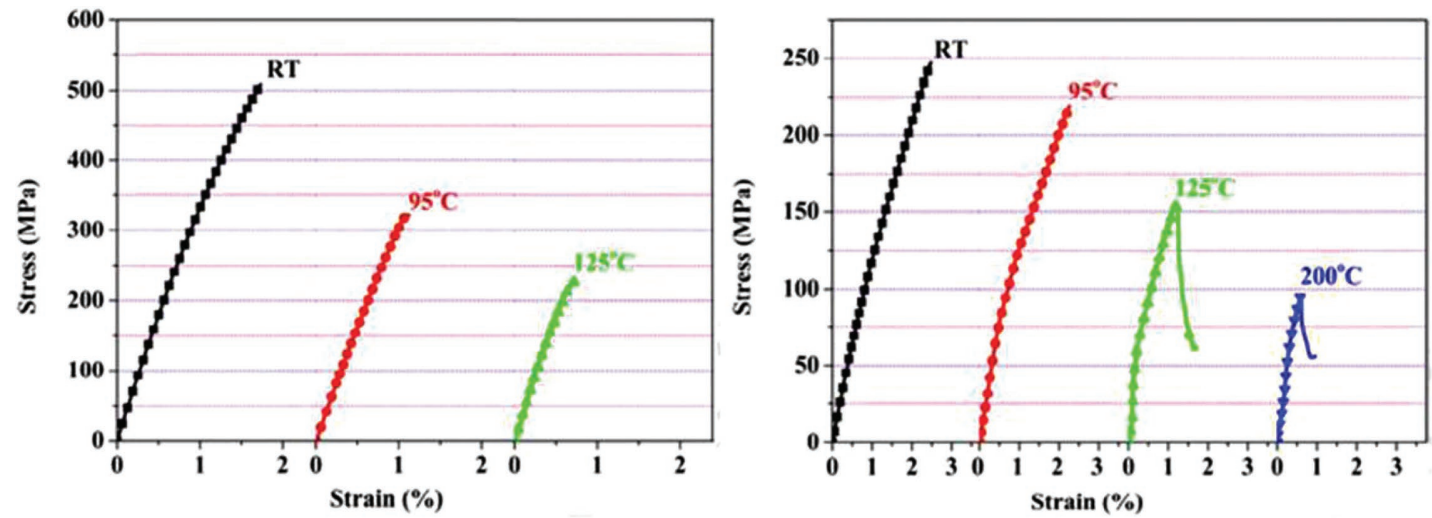

Figure 24. Compressive stress-strain curves of unnotched (left) and notched (right) specimens at different temperatures. Adapted with permission. [233] Copyright 2017, Elsevier Science Ltd.

(a)

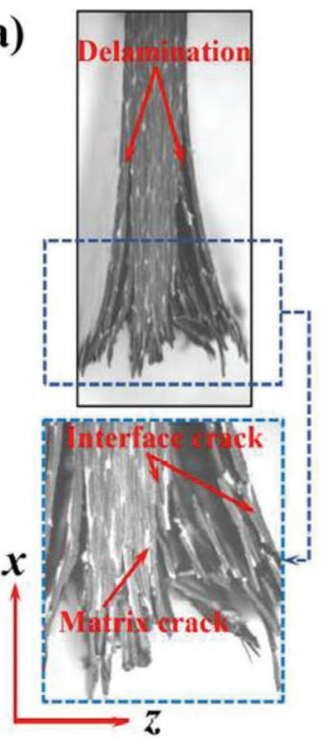

(b)

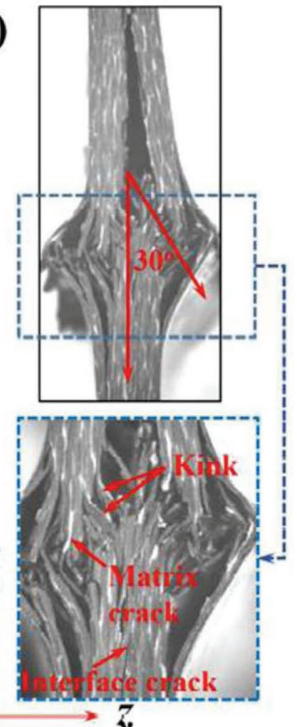

(c)

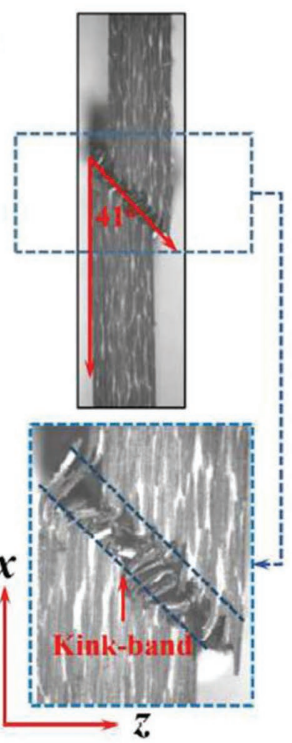

Figure 25. Failure modes of unnotched specimens at different temperatures: a) RT; b) $95^{\circ} \mathrm{C}$; c) $125^{\circ} \mathrm{C}$. Adapted with permission. ${ }^{[233]} \mathrm{Copyright} 2017$, Elsevier Science Ltd.

(a)

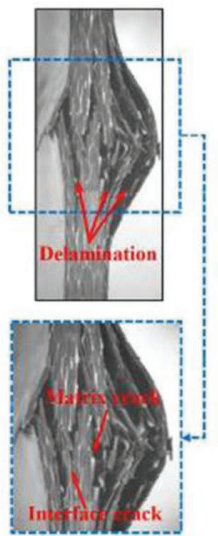

(b)

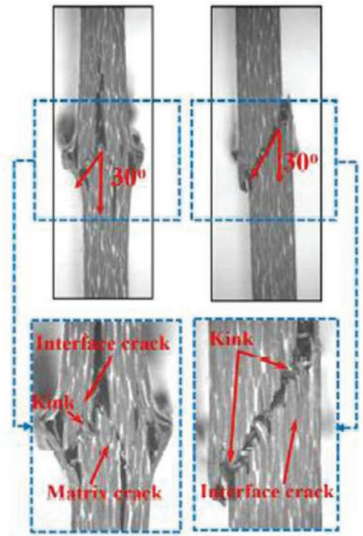

(c)
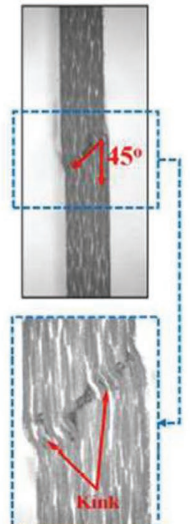

(d)

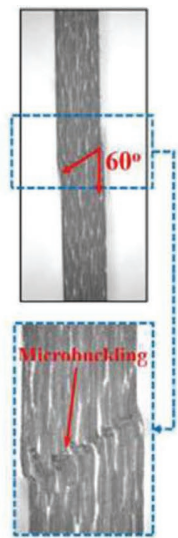

Figure 26. Failure modes of notched specimens at different temperatures: a) RT; b) $95^{\circ} \mathrm{C}$; c) $125^{\circ} \mathrm{C}$; d) $200^{\circ} \mathrm{C}$. Adapted with permission. ${ }^{[233]} \mathrm{Copyright}$ 2017, Elsevier Science Ltd. 

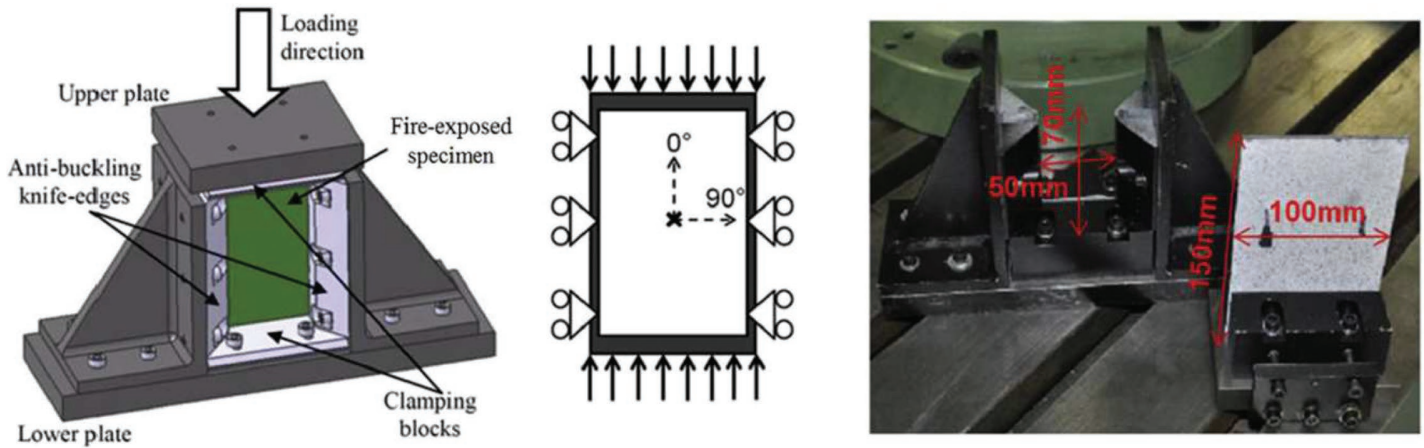

Figure 27. Compression test after fire exposure: experimental setup and anti bulking fixture. Adapted with permission. ${ }^{[234]}$ Copyright 2017 , Elsevier Science Ltd.

brittle matrix degraded more slowly that that with the ductile matrix. ${ }^{[242]}$

In this research, the authors also provided all $\mathrm{S}-\mathrm{N}$ curves for several injection molded thermoplastics and their glass or carbon-filled composites. The measurements were made at room temperature in a uniaxial tension-tension mode with minimum stress/maximum stress equal to 0.1 . There was no evidence of a fatigue limit for any of the thermoplastic matrix composites studied in the range up to $10^{6}$. This study reported that PPS composites failed by a crack propagation mechanism.
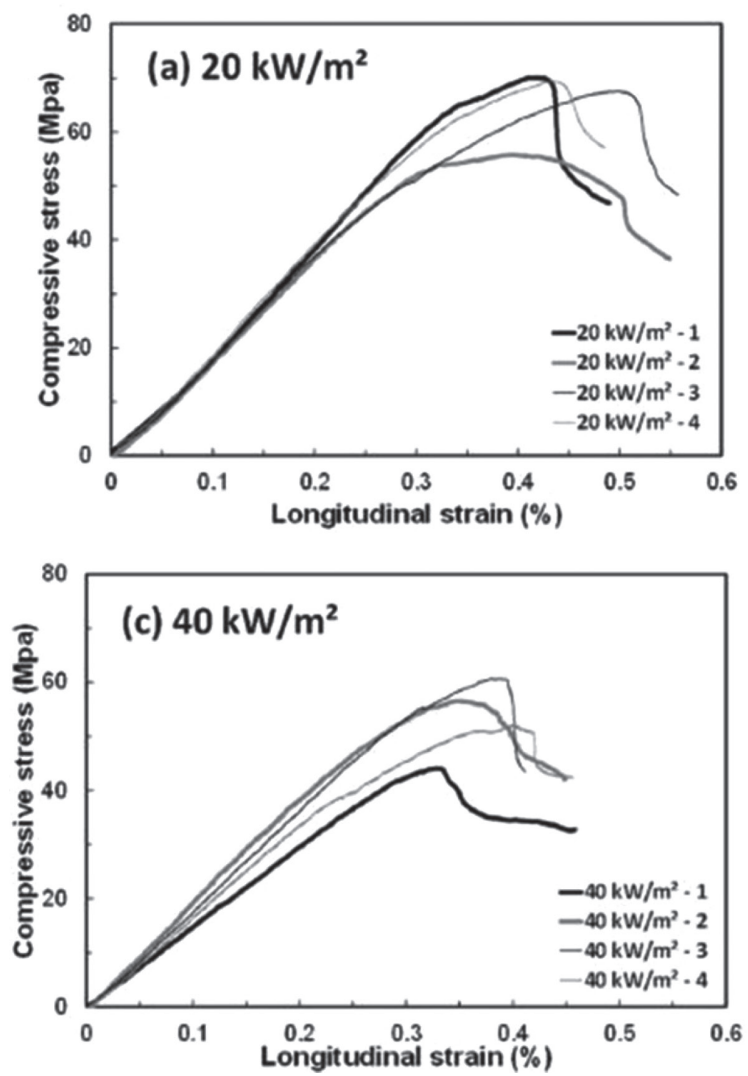

Similarly, the tensile fatigue resistance of $40 \%$ glass fiber/ PPS composites was measured by Oya et al. ${ }^{[243]}$ and they reported that the fatigue strength decreased continuously with the number of loaded applications at $23^{\circ} \mathrm{C}$.

\section{Conclusion}

This review cited a considerable number of publications on the synthesis, characterization, and different applications of
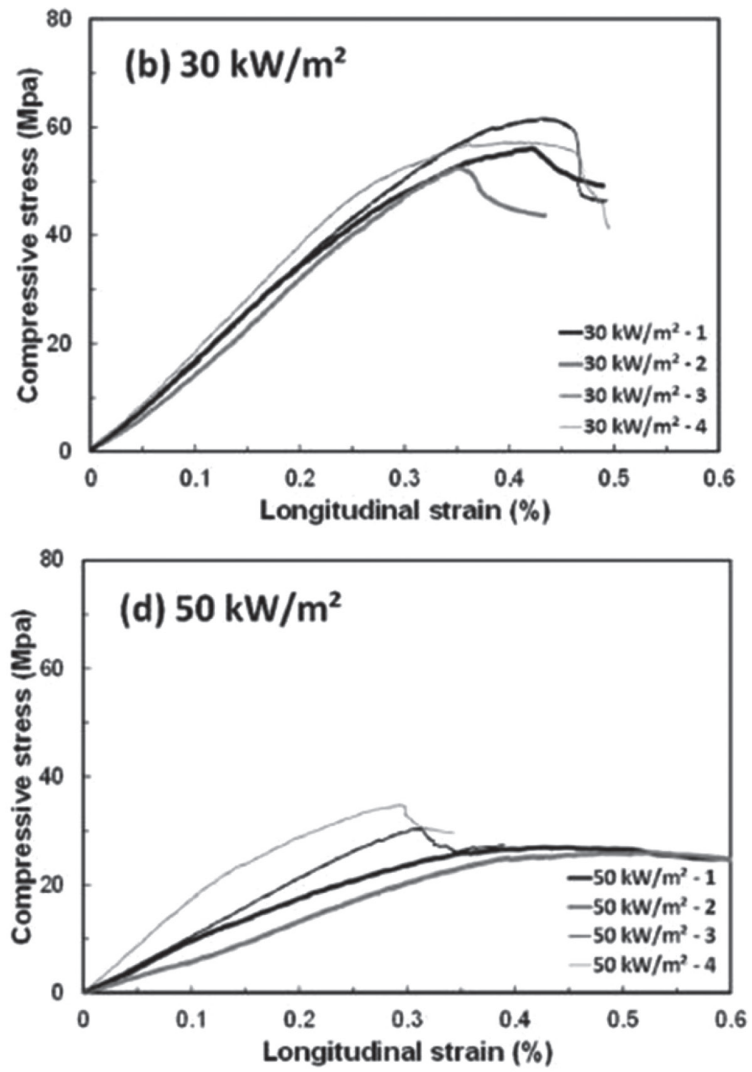

Figure 28. Thermomechanical responses of quasi-isotropic C/PPS laminates subjected to a compressive loading after different prior fire testing conditions. Adapted with permission. ${ }^{[234]}$ Copyright 2017, Elsevier Science Ltd. 


\section{(a) Microscopic buckling at woven-ply level}

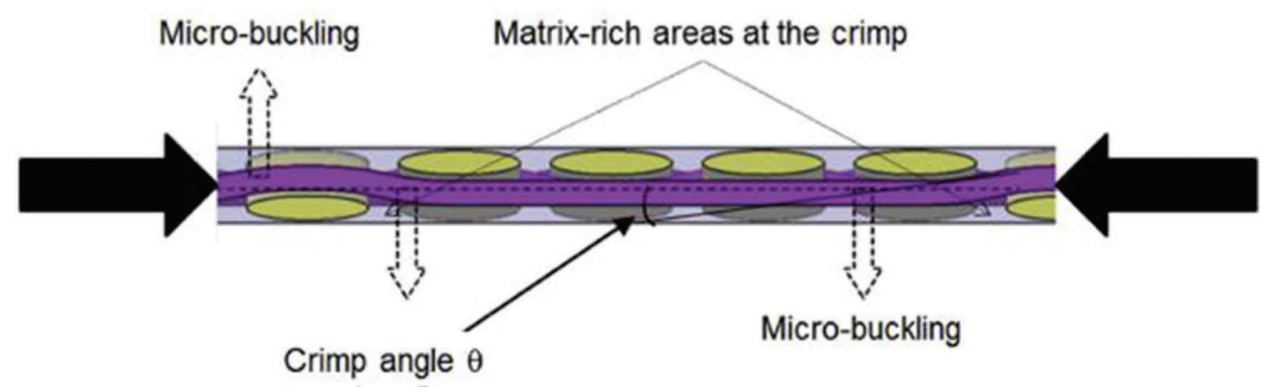

\section{(b) Delamination and global plastic buckling at laminates level}

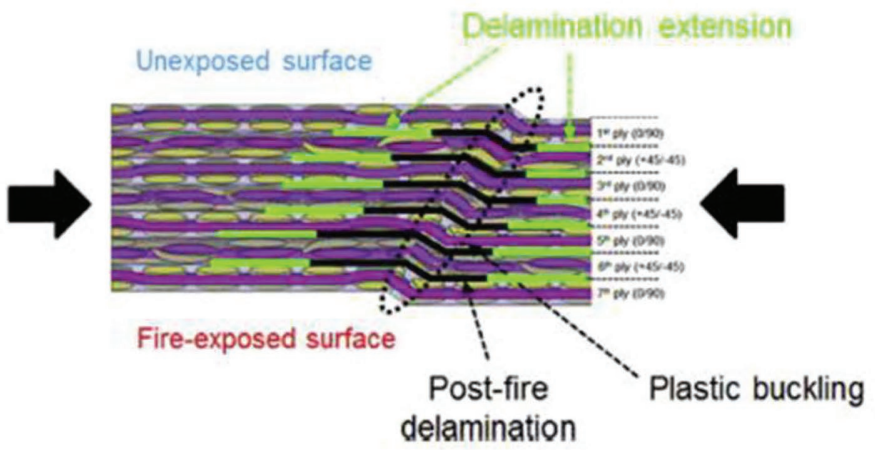

Figure 29. Damage mechanisms in woven-ply quasi-isotropic C/PPS laminates subjected to compression after fire exposure: a) local microbulking of fiber bundles at the crimp in a 5-harness satin weave. b) Delamination and global plastic buckling induced by postfire delamination and the formation of plastic kink bands. Adapted with permission. ${ }^{[234]}$ Copyright 2017, Elsevier Science Ltd.

PPS polymer or PPS-based composite materials. An overview on PPS has been presented in this paper. According to the literature report, it is of importance to combine physicochemical properties with mechanical properties and take

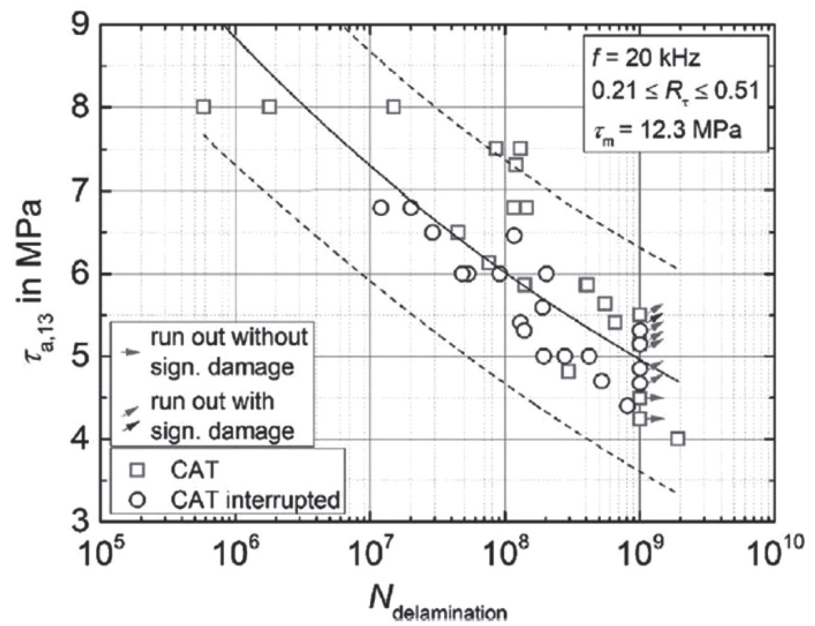

Figure 30. $\mathrm{S}-\mathrm{N}_{\text {delamination }}$ curve for CF-PPS in the very high cycle fatigue regime. Adapted with permission. ${ }^{[24]}$ Copyright 2016, Elsevier Science Ltd. these two aspects into consideration together because of their close relationship. In addition, PPS has been widely used in commercial applications, where high temperatures are required, so it is also crucial to conduct intensive and extensive research in this aspect. Furthermore, it is noteworthy that PPS has many interesting properties that reveal why PPS or PPS-based materials are used in a wide range of applications including automobile parts, coating, chip carriers, wear rings, ball valves, and as a thermoplastic matrix for composite materials, etc. However, it is self-evident that there are still numerous areas that need more study to obtain a better understanding and enlarge the application domains of PPS more extensively and intensively. In particular, there is a lack of knowledge about the long time thermal aging effect on PPS under fatigue conditions or in other harsh environments. In addition, more investigation on the fatigue properties of PPS-based composites materials is needed, which will contribute to the structural applications of PPS as a high-performance engineering material. Moreover, the mechanical degradation of PPS-based composites is also of significance to an in-depth investigation. Undoubtedly, more researchers can find interesting topics of PPS since much more remains to be learned about PPS materials, not only about the science but also about the engineering applications in practice. 


\section{Acknowledgements}

The authors are grateful to Dr. R.C. Benevides and Dr. Manuel Henner (Valeo) for collaboration and fruitful discussions. The Valeo Company is also gratefully acknowledged for providing the material. Financial support from the CASCADE program (2015-2018) under project "FSN Calcul Intensif et Simulation Numérique" by DGE is gratefully acknowledged. The authors also thank the China Scholarship Council (CSC) for their funding (2015-2018) of P.Z.'s thesis.

\section{Conflict of Interest}

The authors declare no conflict of interest.

\section{Keywords}

applications, polyphenylene sulfide materials, processes, synthesis

[1] H. A. Karimi-Varzaneh, P. Carbone, F. Müller-Plathe, Macromolecules 2008, 41, 7211.

[2] H. W. Hill, D. Brady, Polym. Eng. Sci. 1976, 16, 831.

[3] L. C. López, G. L. Wilkes, Polymer 1989, 30, 882.

[4] L. Caramaro, B. Chabert, J. Chauchard, T. Vu-Khanh, Polym. Eng. Sci. 1991, 31, 1279.

[5] M. Favaloro, SAE Technical Paper 2009-01-3242 2009.

[6] N. Christopher, J. Cotter, G. Knight, W. Wright, J. Appl. Polym. Sci. 1968, 12, 863.

[7] G. Ehlers, K. Fisch, W. Powell, J. Polym. Sci., Part A-7: Polym. Chem. 1969, 7, 2955.

[8] L. Yu, S. Bahadur, Q. Xue, Wear 1998, 214, 54.

[9] L. A. Gyurova, K. Friedrich, Tribol. Int. 2011, 44, 603.

[10] Q. Zhao, S. Bahadur, Wear 1998, 217, 62.

[11] Z. Jiang, L. A. Gyurova, A. K. Schlarb, K. Friedrich, Z. Zhang, Compos. Sci. Technol. 2008, 68, 734.

[12] K. Stoeffler, S. Andjelic, N. Legros, J. Roberge, S. B. Schougaard, Compos. Sci. Technol. 2013, 84, 65.

[13] Y. Yang, H. Duan, S. Zhang, P. Niu, G. Zhang, S. Long, X. Wang, J. Yang, Compos. Sci. Technol. 2013, 75, 28.

[14] L. Lopez, G. Wilkes, J. Macromol. Sci., Polym. Rev. 1989, 29, 83.

[15] B. G. Risch, Syst. Comput. Japan 1994, 35, 1.

[16] Y. Zhou, L. Jia, T. Wang, Y. Du, C. Wang, Int. J. Hydrogen Energy 2018, 43, 7356

[17] T. Wang, Y. Jiang, Y. Zhou, Y. Du, C. Wang, Appl. Surf. Sci. 2018, 442, 1.

[18] Y. Shao, F. Xu, W. Li, K. Zhang, C. Zhang, R. Li, Y. Qiu, Composites, Part A 2016, 88, 98.

[19] M. Park, J. H. Park, B. J. Yang, J. Cho, S. Y. Kim, I. Jung, Composites, Part A 2018, 109, 124.

[20] X. Chen, Y. Zheng, Y. Zhang, Catal. Commun. 2018, 105, 16.

[21] M. Cho, Wear 2016, 346-347, 158.

[22] J. Gu, C. Xie, H. Li, J. Dang, W. Geng, Q. Zhang, Polym. Compos. 2014, 35, 611.

[23] H. Qi, L. Zhang, G. Zhang, T. Wang, Q. Wang, J. Colloid Interface Sci. 2018, 514, 615.

[24] D. Luo, M. Chen, J. Xu, X. Yin, J. Wu, S. Chen, L. Wang, H. Wang, Compos. Sci. Technol. 2018, 157, 119.

[25] J. Y. Kim, K. Ahn, S. Y. Jeong, E. D. Jeong, J. S. Jin, J. S. Bae, H. G. Kim, C. R. Cho, Curr. Appl. Phys. 2014, 14, 118.
[26] J. Huang, X. Zhang, L. Bai, S. Yuan, J. Environ. Sci. 2012, 24, 1433.

[27] D. Lian, J. Dai, R. Zhang, M. Niu, Y. Huang, Polym. Degrad. Stab. 2016, $129,77$.

[28] S. Zhou, Q. Zhang, C. Wu, J. Huang, Mater. Des. 2013, 44, 493.

[29] M. C. Lopes de Oliveira, I. J. Sayeg, G. Ett, R. A. Antunes, Int. J. Hydrogen Energy 2014, 39, 16405.

[30] K. Moran, P. Lake, J. Dole, World Pumps 2002, 2002, 27.

[31] B. Liu, Z. Liu, X. Wang, G. Zhang, S. Long, J. Yang, Polym. Test. 2013, 32, 724.

[32] B. Caglar, P. Fischer, P. Kauranen, M. Karttunen, P. Elsner, J. Power Sources 2014, 256, 88.

[33] L. Korugic-Karasz, J. Farugia, Thin Solid Films 2002, 417, 155.

[34] C.-M. Chen, T.-E. Hsieh, M. O. Liu, React. Funct. Polym. 2008, 68, 1307.

[35] M. G. Garrell, B.-M. Ma, A. J. Shih, E. Lara-Curzio, R. O. Scattergood, Mater. Sci. Eng., A 2003, 359, 375.

[36] L. Guo, H. Q. Zhu, Y. B. Sun, App. Mech. Mater. 2012, 184-185, 872.

[37] Z. Hu, L. Li, B. Sun, S. Meng, L. Chen, M. Zhu, Prog. Nat. Sci.: Mater. Int. 2015, 25, 310.

[38] S.-S. Yao, F.-L. Jin, K. Y. Rhee, D. Hui, S.-J. Park, Composites, Part B 2018, 142, 241.

[39] B. Lingesh, B. Rudresh, B. Ravikumar, Procedia Mater. Sci. 2014, 5, 1231.

[40] D. G. Dikobe, A. S. Luyt, Thermochim. Acta 2017, 654, 40.

[41] M. Shirinbayan, J. Fitoussi, N. Abbasnezhad, F. Meraghni, B. Surowiec, A. Tcharkhtchi, Composites, Part B 2017, 131, 8.

[42] A. E. Wiącek, K. Terpiłowski, M. Jurak, M. Worzakowska, Eur. Polym. J. 2016, 78, 1.

[43] K. Laux, A. Jean-Fulcrand, H. Sue, T. Bremner, J. Wong, Polymer 2016, 103, 397.

[44] D. J. Kim, C. H. Park, S. Y. Nam, Int. J. Hydrogen Energy 2016, 41, 7641.

[45] J. da Silva Burgal, L. G. Peeva, S. Kumbharkar, A. Livingston, J. Membr. Sci. 2015, 479, 105.

[46] R. Shrestha, J. Simsiriwong, N. Shamsaei, Polym. Test. 2016, 56, 99.

[47] D. J. Kim, D. H. Choi, C. H. Park, S. Y. Nam, Int. J. Hydrogen Energy 2016, 41, 5793.

[48] D. J. Kim, B.-N. Lee, S. Y. Nam, Int. J. Hydrogen Energy 2017, 42, 23759.

[49] G. Skirbutis, A. Dzingutė, V. Masiliūnaitė, G. Šulcaitė, J. Žilinskas, Stomatologija 2017, 19, 19.

[50] S. Wu, R. B. Ladani, J. Zhang, E. Bafekrpour, K. Chorbani, A. P. Mouritz, A. J. Kinloch, C. H. Wang, Carbon 2015, 94, 607.

[51] D. Quan, A. Ivankovic, Polymer 2015, 66, 16.

[52] D. Carolan, A. Ivankovic, A. Kinloch, S. Sprenger, A. Taylor, Polymer 2016, 97, 179.

[53] M. Chen, J. Yin, R. Jin, L. Yao, B. Su, Q. Lei, Thin Solid Films 2015, $584,232$.

[54] J. Liu, Y. Liu, W. Yang, Q. Ren, F. Li, Z. Huang, J. Power Sources 2018, 396, 265.

[55] T. Deplancke, O. Lame, S. Barrau, K. Ravi, F. Dalmas, Polymer 2017, 111, 204.

[56] L. Melk, N. Emami, Composites, Part B 2018, 146, 20.

[57] L. Dumas, L. Bonnaud, M. Olivier, M. Poorteman, P. Dubois, Eur. Polym. J. 2015, 67, 494.

[58] A. Bhattacharyya, D. Paul, P. Dutta, G. Bhattacharjee, arXiv:1509.010162015.

[59] C. Liu, H. Yan, Q. Lv, S. Li, S. Niu, Carbon 2016, 102, 145.

[60] W. Ciesińska, J. Therm. Anal. Calorim. 2017, 130, 187.

[61] X. Wang, Y. Deng, Y. Li, K. Kjoller, A. Roy, S. Wang, RSC Adv. 2016 6, 76318.

[62] Y. Cui, X. Hou, W. Wang, J. Chang, Materials 2017, 10, 668.

[63] L. Weng, Y. Zhang, X. Zhang, L. Liu, H. Zhang, J. Mater. Sci.: Mater. Electron. 2018, 29, 2831. 
[64] J. Jiao, L.-Z. Zhao, Y. Xia, L. Wang, High Perform. Polym. 2017, 29, 458.

[65] P. Li, T. Li, H. Yan, J. Mater. Sci. Technol. 2017, 33, 1182.

[66] A. D. Macallum, J. Org. Chem. 1948, 13, 154.

[67] R. W. Lenz, W. K. Carrington, J. Polym. Sci., Part A: Polym. Chem. $1959,41,333$

[68] R. W. Lenz, C. E. Handlovits, H. A. Smith, J. Polym. Sci., Part A: Polym. Chem. 1962, 58, 351.

[69] R. W. Lenz, C. E. Handlovits, J. Polym. Sci. 1960, 43, 167.

[70] J. Brydson, Plastics Materials, Heinemann, Butterworth, Malaysia 2013.

[71] C. J. Stacy, J. Appl. Polym. Sci. 1986, 32, 3959.

[72] T. Housaki, K. Satoh, Polym. J. 1988, 20, 1163.

[73] C. C. M. Ma, L. T. Hsiue, W. G. Wu, W. L. Liu, J. Appl. Polym. Sci. 1990, 39, 1399.

[74] N. L. Batista, M. C. Rezende, E. C. Botelho, Polym. Degrad. Stab. 2018, 153, 255.

[75] C. Auer, G. Kalinka, T. Krause, G. Hinrichsen, J. Appl. Polym. Sci. 1994, 51, 407.

[76] L. B. Nohara, E. L. Nohara, A. Moura, J. M. Gonçalves, M. L. Costa, M. C. Rezende, Polímeros 2006, 16, 104.

[77] D. Lian, J. Dai, R. Zhang, M. Niu, J. Therm. Anal. Calorim. 2017, 129, 377.

[78] P. Huo, P. Cebe, J. Polym. Sci., Part B: Polym. Phys. 1992, 30, 239.

[79] S. S. Song, J. L. White, M. Cakmak, Polym. Eng. Sci. 1990, 30, 944.

[80] J. Sheng-Ling, G. Xiao-Yu, Z. Zhi-Yuan, J. Appl. Polym. Sci. 2013, 127, 224.

[81] M. Cho, S. Bahadur, Tribol. Lett. 2007, 25, 237.

[82] S. Deng, L. Cao, Z. Lin, W. Qiu, K. Liang, W. Li, Thermochim. Acta 2014, 584, 51

[83] S. Lee, D.-H. Kim, J.-H. Park, M. Park, H.-I. Joh, B.-C. Ku, Adv. Chem. Eng. Sci. 2013, 03, 145.

[84] S. X. Lu, P. Cebe, J. Appl. Polym. Sci. 1996, 61, 473.

[85] D. Brady, J. Appl. Polym. Sci. 1976, 20, 2541.

[86] J. Chung, J. Bodziuch, P. Cebe, J. Mater. Sci. 1992, 27, 5609.

[87] G. P. Desio, L. Rebenfeld, J. Appl. Polym. Sci. 1992, 44, 1989

[88] L. Ye, T. Scheuring, K. Friedrich, J. Mater. Sci. 1995, 30, 4761.

[89] D. Lu, Y. W. Mai, R. K. Li, L. Ye, Macromol. Mater. Eng. 2003, 288, 693.

[90] N. Nishihata, T. Koizumi, Y. Ichikawa, T. Katto, Polym. Eng. Sci. 1998, 38, 403.

[91] P. Liu, R. B. Dinwiddie, J. K. Keum, R. K. Vasudevan, S. Jesse, N. A. Nguyen, J. M. Lindahl, V. Kunc, Compos. Sci. Technol. 2018, 168, 263.

[92] R. K. Goyal, K. R. Kambale, S. S. Nene, B. S. Selukar, S. Arbuj, U. P. Mulik, Mater. Chem. Phys. 2011, 128, 114.

[93] S. Pappadà, A. Salomi, J. Montanaro, A. Passaro, A. Caruso, A. Maffezzoli, Aerosp. Sci. Technol. 2015, 43, 314.

[94] R. T. Young, D. G. Baird, Composites, Part B 2000, 31, 209.

[95] A. Miller, C. Wei, A. G. Gibson, Composites, Part A 1996, 27, 49.

[96] M. Hou, L. Ye, Composite Technologies for 2020 (Eds: L. Ye, Y. W. Mai, Z. Su), Woodhead Publishing, Cambridge, UK 2004, p. 805.

[97] S. M. A. Durani, E. E. Khawaja, H. M. Masoudi, Z. Bastl, J. Šubrt, A. Galíková, J. Pola, J. Anal. Appl. Pyrolysis 2005, 73, 145.

[98] H. Wang, J. Zhao, Y. Zhu, Y. Meng, Y. Zhu, J. Colloid Interface Sci. 2013, 402, 253.

[99] S. Radhakrishnan, B. T. S. Ramanujam, A. Adhikari, S. Sivaram, J. Power Sources 2007, 163, 702.

[100] H. M. El-Dessouky, C. A. Lawrence, Composites, Part B 2013, 50, 91.

[101] C. Lv, H. Wang, Z. Liu, W. Zhang, C. Wang, R. Tao, M. Li, Y. Zhu, Appl. Surf. Sci. 2018, 435, 903.

[102] H. D. Coale, US3954932A, 1976.
[103] M. Akatsu, E. Nakano, H. Endo, K. Sonoda, US5178813A, 1993.

[104] H. N. Beck, R. D. Mahoney, H. S. Wan, C.-C. Chau, T. M. Finney, R. A. Wessling, J. Kawamoto, M. F. Sonnenschein, US5246647, 1993.

[105] S. Fukata, US4454189A, 1984.

[106] J. S. Reinaldo, L. M. Pereira, E. D. S. Silva, M. M. Ueki, E. N. Ito, Polym. Test. 2018, 67, 257.

[107] J. Yang, X. Qi, N. Zhang, T. Huang, Y. Wang, Composites Commun. 2018, 7, 51.

[108] A. Sangroniz, A. Gonzalez, L. Martin, L. Irusta, M. Iriarte, A. Etxeberria, Polym. Degrad. Stab. 2018, 151, 25.

[109] E. Meaurio, E. Sanchez-Rexach, E. Zuza, A. Lejardi, A. D. P. SanchezCamargo, J.-R. Sarasua, Polymer 2017, 113, 295.

[110] H. Shinzawa, J. Mizukado, Spectrochim. Acta, Part A 2018, 192, 236.

[111] J. Chen, X. Cui, K. Sui, Y. Zhu, W. Jiang, Compos. Sci. Technol. 2017, 140, 99.

[112] P. S. Kumar, A. Sakunthala, M. V. Reddy, M. Prabu, Solid State Ionics 2018, 319, 256.

[113] A. Shubha, S. R. Manohara, L. Gerward, J. Mol. Liq. 2017, 247, 328.

[114] N. Halawani, J. L. Augé, H. Morel, O. Gain, S. Pruvost, Composites, Part B 2017, 110, 530.

[115] Q. Guo, Y. Chen, J. Zhang, Z. Yao, Polym. Test. 2017, 63, 587.

[116] J. Gao, H. Wang, X. Huang, M. Hu, H. Xue, R. K. Y. Li, Compos. Sci. Technol. 2018, 161, 135.

[117] O. J. Botlhoko, J. Ramontja, S. S. Ray, Polymer 2018, 139, 188.

[118] N. Mehra, L. Mu, T. Ji, Y. Li, J. Zhu, Compos. Sci. Technol. 2017, $151,115$.

[119] Y.-L. Xu, A. Q. Dayo, M. Derradji, J. Wang, W.-B. Liu, S. Song, T. Tang, React. Funct. Polym. 2018, 123, 97.

[120] K. Lewandowska, A. Sionkowska, S. Grabska, B. Kaczmarek, Int. J. Biol. Macromol. 2016, 92, 371.

[121] A. R. Zanjanijam, S. Hakim, H. Azizi, Polym. Test. 2018, 66, 48.

[122] N. Z. Tomić, A. D. Marinković, Đ. Veljović, K. Trifković, S. Lević, V. Radojević, R. Jančić Heinemann, Int. J. Adhes. Adhes. 2018, 81, 11.

[123] H. Y. Ang, J. Chan, D. Toong, S. S. Venkatraman, S. J. Chia, Y. Y. Huang, J. Mech. Behav. Biomed. Mater. 2018, 79, 64.

[124] N. Zheng, W. Sun, H.-Y. Liu, Y. Huang, J. Gao, Y.-W. Mai, Compos. Sci. Technol. 2018, 159, 180.

[125] X. He, Z. Qiu, Polym. Test. 2018, 67, 421.

[126] R. Malinowski, Chem. Phys. Lett. 2016, 662, 91.

[127] Y. Kanca, P. Milner, D. Dini, A. A. Amis, J. Mech. Behav. Biomed. Mater. 2018, 78, 36.

[128] R. A. Borges, D. Choudhury, M. Zou, Tribol. Int. 2018, 122, 1.

[129] M. T. Mathew, J. Novo, L. A. Rocha, J. A. Covas, J. R. Gomes, Tribol. Int. 2010, 43, 1400.

[130] W. Luo, Q. Liu, Y. Li, S. Zhou, H. Zou, M. Liang, Composites, Part B 2016, 91, 579 .

[131] J. Xing, Q.-Q. Ni, B. Deng, Q. Liu, Compos. Sci. Technol. 2016, 134, 184.

[132] Z. Chen, T. Li, Y. Yang, X. Liu, R. Lv, Wear 2004, 257, 696.

[133] Z. Luo, Z. Zhang, W. Wang, W. Liu, Surf. Coat. Technol. 2009, 203, 1516.

[134] R. Steffen, M. Meir, J. Rekstad, B. Röder, Polymer 2018, 136, 71.

[135] H.-H. Ren, D.-X. Xu, G.-M. Yan, G. Zhang, X.-J. Wang, S.-R. Long, J. Yang, Compos. Sci. Technol. 2017, 146, 65.

[136] K. Zhang, G. Zhang, B. Liu, X. Wang, S. Long, J. Yang, Compos. Sci. Technol. 2014, 98, 57.

[137] Y. Yang, B. Li, L. Dong, J. Appl. Polym. Sci. 1996, 59, 531.

[138] J. Seppälä, M. Heino, C. Kapanen, J. Appl. Polym. Sci. 1992, 44, 1051

[139] M. T. Heino, J. V. Seppälä, J. Appl. Polym. Sci. 1992, 44, 2185.

[140] W. Tang, X. Hu, J. Tang, R. Jin, J. Appl. Polym. Sci. 2007, 106, 2648.

[141] K. Mai, M. Zhang, H. Zeng, S. Qi, J. Appl. Polym. Sci. 1994, 51, 57.

[142] R. T. Alvarez, US4017155A, 1977.

[143] K. Kubo, J. Masamoto, J. Appl. Polym. Sci. 2002, 86, 3030. 
[144] M. Ajbani, A. Auerbach, K. Feng, US8162732B2, 2012.

[145] S. Kadoi, H. Yabe, K. Kobayashi, US5488084A, 1996.

[146] S. Lim, J. Kim, M. Park, C. R. Choe, J. Lee, D. Kim, Polym. Eng. Sci. 1996, 36, 2502.

[147] H. T. Oyama, M. Matsushita, M. Furuta, Polym. J. 2011, 43, 991.

[148] V. Shingankuli, J. Jog, V. Nadkarni, J. Appl. Polym. Sci. 1988, 36, 335.

[149] R. Zhang, Y. Huang, M. Min, Y. Gao, A. Lu, Z. Lu, J. Appl. Polym. Sci. 2008, 107, 2600.

[150] D. Wu, Y. Zhang, M. Zhang, L. Wu, J. Appl. Polym. Sci. 2007, 105, 739.

[151] K. Mai, S. Zhang, Q. Gao, H. Zeng, J. Appl. Polym. Sci. 2000, 78, 1579.

[152] G. Shonaike, S. Yamaguchi, M. Ohta, H. Hamada, Z. Maekawa, M. Nakamichi, W. Kosaka, K. Toi, Polym. Eng. Sci. 1995, 35, 240.

[153] H. Zeng, M. Kancheng, Die Makromolekulare Chemie 1986, 187, 1787.

[154] J. Wang, K.-X. Li, H.-W. He, J.-L. Wang, G.-H. Sun, Colloids Surf. A 2011, 377, 330

[155] S. Yu, W. Wong, X. Hu, Y. Juay, J. Appl. Polym. Sci. 2009, 113, 3477.

[156] J. Yang, T. Xu, A. Lu, Q. Zhang, H. Tan, Q. Fu, Compos. Sci. Technol. 2009, 69, 147.

[157] D. Wu, L. Wu, W. Zhou, T. Yang, M. Zhang, Polym. Eng. Sci. 2009, 49, 1727.

[158] A. M. Díez-Pascual, M. Naffakh, C. Marco, G. Ellis, Composites, Part A 2012, 43, 603.

[159] S. Yu, W. M. Wong, X. Hu, Y. K. Juay, J. Appl. Polym. Sci. 2009, 113 3477.

[160] M. S. Han, Y. K. Lee, H. S. Lee, C. H. Yun, W. N. Kim, Chem. Eng. Sci. 2009, 64, 4649.

[161] A. Kojima, T. Nishi, H. Iwamura, US7569635B2, 2009.

[162] J. O. Reed, R. D. Mathis, US4418029A, 1983.

[163] J. C. Goossens, R. F. Sieloff, US4937026A, 1990

[164] M. C. L. de Oliveira, I. J. Sayeg, G. Ett, R. A. Antunes, Int. J. Hydrogen Energy 2014, 39, 16405.

[165] H. Izutsu, T. Yamaguchi, US4703074A, 1987.

[166] H. Zou, N. Ning, R. Su, Q. Zhang, Q. Fu, J. Appl. Polym. Sci. 2007, 106, 2238.

[167] D. M. Dean, R. J. Arhart, US6608136B1, 2003.

[168] K. E. Mitchell, US7312300B2, 2007.

[169] K. Kodama, T. Sugata, T. Yamanaka, US20100048777A1, 2010.

[170] N. Anagreh, L. Dorn, C. Bilke-Krause, Int. J. Adhes. Adhes. 2008, 28, 16.

[171] T. Asano, US6531530B2, 2003.

[172] R. D. Mathis, J. O. Reed, US4535117A, 1985

[173] Y. Bo, C. Yanmo, Y. Hao, S. Bin, Z. Meifang, J. Appl. Polym. Sci. 2009, 111, 1900.

[174] P. Zuo, A. Tcharkhtchi, M. Shirinbayan, J. Fitoussi, F. Bakir, Polym. Adv. Technol. 2018, In press.

[175] P. Zuo, J. Fitoussi, M. Shirinbayan, F. Bakir, A. Tcharkhtchi, Polym. Eng. Sci. 2018, In press.

[176] M. Bonnet, K.-D. Rogausch, J. Petermann, Colloid Polym. Sci. 1999, 277, 513.

[177] R. Goyal, P. Jadhav, A. Tiwari, J. Electron. Mater. 2011, 40.

[178] S. Y. Pak, H. M. Kim, S. Y. Kim, J. R. Youn, Carbon 2012, 50, 4830.

[179] A. M. Díez-Pascual, J. Guan, B. Simard, M. A. Gómez-Fatou, Composites, Part A 2012, 43, 1007.

[180] M. O. Khan, S. N. Leung, E. Chan, H. E. Naguib, F. Dawson, V. Adinkrah, Polym. Eng. Sci. 2013, 53, 2398.

[181] J. Gu, J. Du, J. Dang, W. Geng, S. Hu, Q. Zhang, RSC Adv. 2014, 4, 22101.

[182] J. Gu, Y. Guo, X. Yang, C. Liang, W. Geng, L. Tang, N. Li, Q. Zhang, Composites, Part A 2017, 95, 267.

[183] B. Yan, Y. Chen, H. You, B. Sun, M. Zhu, J. Appl. Polym. Sci. 2009, $111,1278$.

[184] X. G. Li, M. R. Huang, H. Bai, Y. L. Yang, J. Appl. Polym. Sci. 2002, 83, 2053.
[185] C. Teng, J. Liu, N. Mao, X. Tian, presented at the Int. Conf. on Chemical, Material and Food Engineering (CMFE-2015), Kunming, Yunnan, China, July 2015.

[186] I. Bhardwaj, V. Kumar, A. Das, Thermochim. Acta 1989, 144, 165.

[187] D. Q. Chang, J. X. Liu, N. Mao, B. Z. Chen, Adv. Mater. Res. 2013 663, 988.

[188] C.-C. M. Ma, H.-C. Hsia, W.-L. Liu, J.-T. Hu, J. Thermoplast. Compos. Mater. 1988, 1, 39.

[189] W. Tanthapanichakoon, M. Furuuchi, K.-H. Nitta, M. Hata, S. Endoh, Y. Otani, Polym. Degrad. Stab. 2006, 91, 1637.

[190] L. Perng, Polym. Degrad. Stab. 2000, 69, 323.

[191] T. Yamashita, T. Kudo, K. Horie, S. Maeda, K. Nagata, Polym. Degrad. Stab. 1993, 39, 279.

[192] Y. Cohen, Z. Aizenshtat, J. Anal. Appl. Pyrolysis 1993, 27, 131.

[193] R. Black, C. List, R. Wells, J. Appl. Chem. 1967, 17, 269.

[194] P. Deslauriers, J. F. Geibel, P. Das, Angew. Makromol. Chem. 1997, 247, 45.

[195] S. G. Pantelakis, C. V. Katsiropoulos, P. Lefebure, J. Appl. Polym. Sci. 2008, 107, 3190.

[196] L. N. Zhang, X. H. Zhang, H. M. Yang, Q. Zheng, Chin. Chem. Lett. 2012, 23, 478.

[197] B. Vieille, W. Albouy, L. Taleb, Composites, Part B 2016, 90, 278.

[198] D. Wu, L. Wu, J. Wang, Y. Sun, M. Zhang, Mater. Chem. Phys. 2011, 128, 274.

[199] T. Hou, H. Chen, Polymer 2012, 53, 2509.

[200] Y. Guo, R. D. Bradshaw, Polymer 2009, 50, 4048.

[201] T. H. Lee, F. Y. C. Boey, N. L. Loh, Compos. Sci. Technol. 1993, 49, 217.

[202] A. M. Díez-Pascual, M. Naffakh, Mater. Chem. Phys. 2012, 135, 348.

[203] J. Scobbo, C. Hwang, Polym. Eng. Sci. 1994, 34, 1744.

[204] D. Wu, L. Wu, J. Wang, Y. Sun, M. Zhang, Mater. Chem. Phys. 2011, 128, 274.

[205] L. Caramaro, B. Chabert, J. Chauchard, T. Vu-Khanh, Polym. Eng. Sci. 1991, 31, 1279.

[206] A. El-Hadi, R. Schnabel, E. Straube, G. Müller, S. Henning, Polym. Test. 2002, 21, 665 .

[207] S. L. Bo, B. C. Chun, Y. C. Chung, Fibers Polym. 2004, 5, 145.

[208] P. Gulgunje, Ph.D. Thesis, University of Tennesse, Knoxville, TN 2010.

[209] C. Hou, B. Zhao, J. Yang, Z. Yu, Q. Wu, J. Appl. Polym. Sci. 1995 56,581

[210] N. Saba, M. T. Paridah, M. Jawaid, Constr. Build. Mater. 2015, 76, 87.

[211] M. Abdelmouleh, S. Boufi, M. N. Belgacem, A. Dufresne, Compos. Sci. Technol. 2007, 67, 1627.

[212] K. L. Pickering, M. A. Efendy, T. M. Le, Composites, Part A 2016, 83, 98.

[213] Q. Hou, D. W. Grijpma, J. Feijen, Biomaterials 2003, 24, 1937.

[214] M. E. Sayer, US4740150A, 1988.

[215] L. Shujian, Z. Lihua, C. Rong, Z. Liran, Z. Yuanqi, Rare Met. Mater. Eng 2016, 45, 2282

[216] A. Chambers, J. Earl, C. Squires, M. Suhot, Int. J. Fatigue 2006, 28, 1389.

[217] K. Zhang, G. Zhang, B. Liu, X. Wang, S. Long, J. Yang, Compos. Sci. Technol. 2014, 98, 57.

[218] W. Luo, Q. Liu, Y. Li, S. Zhou, H. Zou, M. Liang, Composites, Part B 2016, 91, 579.

[219] D.-J. Zhou, L.-B. Dai, H. Ni, G.-L. Hui, S.-G. Yuan, Chin. Chem. Lett. 2014, 25, 221.

[220] P. Zuo, R. C. Benevides, M. A. Laribi, J. Fitoussi, M. Shirinbayan, F. Bakir, A. Tcharkhtchi, Composites, Part B 2018, 145, 173.

[221] W. Albouy, B. Vieille, L. Taleb, Composites, Part A 2013, 49, 165.

[222] D. Blond, B. Vieille, M. Gomina, L. Taleb, J. Reinf. Plast. Compos. 2014, 33, 1656

[223] A. Lou, T. Murtha, J. Mater. Eng. 1988, 10, 109.

[224] H. Zhai, X. Zhou, L. Fang, A. Lu, J. Appl. Polym. Sci. 2010, 115, 2019. 
[225] H.-J. Park, B. C. Chun, Polym. Bull. 1996, 37, 103.

[226] Y. Ma, P. Cong, X. Liu, R. Lv, T. Li, J. Macromol. Sci., Part B 2014, 53, 1786.

[227] Y. Wang, J. Zhang, G. Fang, J. Zhang, Z. Zhou, S. Wang, Compos. Struct. 2018, 185, 435.

[228] T. Sınmazçelik, Mater. Des. 2006, 27, 270.

[229] D. Kytýr, T. Fıla, J. Valach, M. Šperl, U.P.B. Sci. Bull. 2013, 75, 157

[230] T. Yýlmaz, T. Sýnmazçelik, Mater. Des. 2007, 28, 520.

[231] N. Koutras, I. F. Villegas, R. Benedictus, Composites, Part A 2018, 105, 57.

[232] A. Costa, E. C. Botelho, L. Pardini, J. Appl. Polym. Sci. 2010, 118, 180.

[233] Y. Wang, J. Zhang, J. Zhang, Z. Zhou, G. Fang, S. Wang, Compos. B. Eng. 2017, 133, 68.

[234] M. Maaroufi, Y. Carpier, B. Vieille, L. Gilles, A. Coppalle, F. Barbe, Composites, Part B 2017, 119, 101.

[235] B. Vieille, V. M. Casado, C. Bouvet, Compos. Struct. 2013, 101, 9.
[236] B. Vieille, V. M. Casado, C. Bouvet, Compos. Struct. 2014, 110, 207.

[237] M. O. Khan, S. N. Leung, E. Chan, H. E. Naguib, F. Dawson, V. Adinkrah, Polym. Eng. Sci. 2013, 53, 2398.

[238] J. Zhou, A. D’Amore, Y. Yang, T. He, B. Li, L. Nicolais, Appl. Compos. Mater. 1994, 1, 183.

[239] I. De Baere, W. Van Paepegem, J. Degrieck, Polym. Test. 2013, 32, 1273.

[240] M. Akatsu, W. Van Paepegem, J. Degrieck, presented at the 15th European Conf. on Composite Materials (ECCM15-2012), Department of Materials Science and Engineering, Ghent University 2012.

[241] D. Backe, F. Balle, Compos. Sci. Technol. 2016, 126, 115.

[242] J. F. Mandell, D. Huang, F. McGarry, Polym. Compos. 1981, 2, 137.

[243] N. Oya, H. Hamada, Composites, Part A 1997, 28, 823.

[244] M. Rezakazemi, M. Sadrzadeh, T. Matsuura, Prog. Energy Combust. Sci. 2018, 66, 1.

[245] J. M. Chen, E. Woo, J. Appl. Polym. Sci. 1995, 57, 877. 